\title{
Land- und Forstwirtschaft, Fischerei
}

Michael Köhl, Christian Möllmann, Jörg Fromm, Gerd Kraus, Volker Mues

\subsection{Einleitung - 150}

7.2 Land- und Forstwirtschaft - 150

7.2.1 Land- und Forstwirtschaft als Ursache des Klimawandels - 152

7.2.2 Auswirkungen des Klimawandels auf die Land- und Forstwirtschaft - 154

7.2.3 Minderungen - 160

7.2.4 Anpassung an den Klimawandel - 162

7.2.5 Zusammenfassung: Mögliche Auswirkungen des Klimawandels auf die Land- und Forstwirtschaft in der Metropolregion - 164

7.3 Fischerei - 165

7.3.1 Einleitung: Fischerei in der Nordsee und der Einfluss des Klimawandels - 165

7.3.2 Klimabedingte Änderungen in der Biologie der lebenden marinen Ressourcen - 166

7.3.3 Konsequenzen der biologischen Änderungen für die Fischerei - 168

7.3.4 Zusammenfassung: Mögliche Auswirkungen des Klimawandels für die deutsche Fischerei in der Nordsee - 169

Literatur - 169 
- Tab. 7.1 Bruttowertschöpfung. (Statistische Ämter des Bundes und der Länder 2015; eigene Berechnungen)

\begin{tabular}{|c|c|c|c|c|}
\hline \multirow[t]{2}{*}{ Kreise und kreisfreie Städte } & \multirow{2}{*}{$\begin{array}{l}\text { Insgesamt } \\
\text { Tsd. EUR }\end{array}$} & \multicolumn{2}{|c|}{ Land- und Forstwirtschaft, Fischerei } & \multirow{2}{*}{$\begin{array}{l}\text { Anteil an der BWS der Land- und Forstwirt- } \\
\text { schaft, Fischerei } \\
\%\end{array}$} \\
\hline & & Tsd. EUR & $\%$ & \\
\hline Lübeck & 6.468 .878 & 5847 & 0,1 & 0,35 \\
\hline Neumünster & 2.285 .996 & 7933 & 0,3 & 0,48 \\
\hline Dithmarschen & 3.216 .773 & 116.836 & 3,6 & 7,02 \\
\hline Herzogtum Lauenburg & 3.368 .314 & 53.058 & 1,6 & 3,19 \\
\hline Ostholstein & 3.844 .180 & 60.971 & 1,6 & 3,66 \\
\hline Pinneberg & 6.775 .357 & 84.397 & 1,2 & 5,07 \\
\hline Segeberg & 6.049 .648 & 72.935 & 1,2 & 4,38 \\
\hline Steinburg & 3.372 .566 & 77.985 & 2,3 & 4,69 \\
\hline Stormarn & 5.976 .637 & 38.263 & 0,6 & 2,30 \\
\hline Hamburg & 8.496 .7698 & 93.726 & 0,1 & 5,63 \\
\hline Cuxhaven & 3.420 .229 & 161.359 & 4,7 & 9,70 \\
\hline Harburg & 4.045 .402 & 67.427 & 1,7 & 4,05 \\
\hline Lüchow-Dannenberg & 922.517 & 51.204 & 5,6 & 3,08 \\
\hline Lüneburg & 3.606 .832 & 549.86 & 1,5 & 3,31 \\
\hline Rotenburg (Wümme) & 3.978 .563 & 132.233 & 3,3 & 7,95 \\
\hline Heidekreis & 3.425 .432 & 71.332 & 2,1 & 4,29 \\
\hline Stade & 4.530 .509 & 111.871 & 2,5 & 6,72 \\
\hline Uelzen & 1.912 .231 & 80.834 & 4,2 & 4,86 \\
\hline Nordwestmecklenburg & 2.862 .129 & 106.378 & 3,7 & 6,39 \\
\hline Ludwigslust-Parchim & 3.795 .953 & 214.049 & 5,6 & 12,87 \\
\hline Gesamt & 158.825 .844 & 1.663 .624 & & \\
\hline
\end{tabular}

\subsection{Einleitung}

Land- und Forstwirtschaft sind zusammen mit der Fischerei ein wichtiger Wirtschaftsfaktor der Metropolregion Hamburg (MRH). In den dörflichen und weit von der Hansestadt entfernten Regionen ist die Landwirtschaft ein bedeutender Arbeitgeber (Schulze et al. 2011; Statistisches Amt für Hamburg und Schleswig Holstein 2013; Statistische Ämter des Bundes und der Länder 2015). Fischerei, Land- und Forstwirtschaft tragen etwa $1 \%$ zur Bruttowertschöpfung der MRH bei, wobei der Anteil in den Landkreisen Lüchow-Dannenberg und Ludwigslust-Parchim bei über $5 \%$ liegt ( Tab. 7.1). Die geringsten Beiträge zur Bruttowertschöpfung (rund 0,1 \%) werden in den kreisfreien Städten Lübeck und Hamburg erzielt. In Hamburg werden rund $6 \%$ der gesamten Bruttowertschöpfung der Land- und Forstwirtschaft und Fischerei erzielt. Dieser im Vergleich zur forst- und landwirtschaftlichen Fläche hohe Anteil an der Bruttowertschöpfung ist auf die Ausrichtung auf den wenig flächenintensiven und hoch produktiven Gartenbau zurückzuführen.

Aufgrund der Unterschiede zwischen terrestrischer und maritimer Biosphäre sowie der dadurch bedingten unterschiedlichen Produktionsbedingungen werden im Folgenden Land- und
Forstwirtschaft und Fischerei getrennt dargestellt. Im Gegensatz zum Klimabericht 2011 (von Storch und Claussen 2011) befasst sich der Teilbereich Land- und Forstwirtschaft intensiv mit Wäldern, deren langfristige Produktionszeiträume eine besondere Herausforderung für die Anpassung an erwartete zukünftige Klimaveränderungen darstellen.

\subsection{Land- und Forstwirtschaft}

Die Hälfte der Landesfläche Deutschlands wird landwirtschaftlich genutzt. Etwa 270.000 landwirtschaftliche Betriebe beschäftigen rund 670.000 Menschen und erwirtschaften Waren im Wert von 500 Mrd. Euro im Jahr (IAB 2013; Statistische Ämter des Bundes und der Länder 2015). Etwa ein Drittel Deutschlands ist von Wäldern bedeckt, die mit einem durchschnittlichen Holzvorrat von $321 \mathrm{~m}^{3} / \mathrm{ha}$ zu den vorratsreichsten in ganz Europa zählen. Auch in der MRH prägen Land- und Forstwirtschaft das Landschaftsbild. Landwirtschaftsflächen nehmen rund $62 \%$ der Bodenfläche der MRH ein, ein Fünftel ist mit Wäldern bedeckt (• Tab. 7.2). Die Unterschiede zwischen den einzelnen Kreisen und kreisfreien Städten sind aber beachtlich. Lüchow-Dannen- 
- Tab. 7.2 Boden-, Landwirtschafts- und Waldfläche. (Statistische Ämter des Bundes und der Länder 2015; eigene Berechnungen)

\begin{tabular}{|c|c|c|c|c|c|}
\hline \multirow{3}{*}{ Kreise und kreisfreie Städte } & \multirow{3}{*}{$\begin{array}{l}\text { Bodenfläche } \\
\text { [ha] }\end{array}$} & \multicolumn{3}{|c|}{ Landwirtschaftsfläche } & \multirow{3}{*}{$\begin{array}{l}\text { Waldfläche } \\
\text { [ha] }\end{array}$} \\
\hline & & Gesamt & Moor & Heide & \\
\hline & & [ha] & [ha] & [ha] & \\
\hline Lübeck & 21.421 & 6965 & 2 & 18 & 3092 \\
\hline Neumünster & 7163 & 3025 & 188 & 2 & 324 \\
\hline Dithmarschen & 142.809 & 109.092 & 432 & 93 & 5306 \\
\hline Herzogtum Lauenburg & 126.297 & 73.461 & 311 & 314 & 32.406 \\
\hline Ostholstein & 139.259 & 100.541 & 153 & 19 & 14.158 \\
\hline Pinneberg & 66.425 & 41.131 & 98 & 130 & 5855 \\
\hline Segeberg & 134.441 & 89.173 & 1100 & 359 & 23.323 \\
\hline Steinburg & 105.614 & 76.679 & 833 & 117 & 9880 \\
\hline Stormarn & 76.629 & 50.899 & 303 & 11 & 10.495 \\
\hline Hamburg & 75.522 & 18.559 & 26 & 658 & 4807 \\
\hline Cuxhaven & 205.777 & 156.350 & 6323 & 565 & 17.663 \\
\hline Harburg & 124.497 & 65.173 & 829 & 1770 & 35.448 \\
\hline Lüchow-Dannenberg & 122.065 & 63.463 & 66 & 746 & 45.261 \\
\hline Lüneburg & 132.350 & 68.130 & 69 & 358 & 42.887 \\
\hline Rotenburg (Wümme) & 207.030 & 146.142 & 6363 & 1574 & 34.384 \\
\hline Heidekreis & 187.367 & 78.532 & 821 & 5285 & 60.495 \\
\hline Stade & 126.602 & 92.044 & 2248 & 202 & 9078 \\
\hline Uelzen & 145.414 & 77.143 & 158 & 545 & 48.698 \\
\hline Nordwestmecklenburg & 211.845 & 151.368 & 292 & 4 & 28.458 \\
\hline Ludwigslust-Parchim & 475.186 & 283.003 & 429 & 352 & 133.891 \\
\hline Gesamt & 2.833 .713 & 1.750 .873 & 21.044 & 13.122 & 565.909 \\
\hline
\end{tabular}

berg, Lübeck, Heidekreis und Uelzen weisen einen Waldflächenanteil von über 30 \% auf, während in Neumünster, Dithmarschen, Pinneberg, Steinburg, Hamburg, Cuxhaven und Stade weniger als $10 \%$ der Bodenfläche von Wäldern bedeckt sind. Auch bei der landwirtschaftlich genutzten Fläche finden sich deutliche Unterschiede: Den geringsten Anteil an Landwirtschaftsflächen weist mit rund $25 \%$ Hamburg auf; in Dithmarschen, Ostholstein, Steinburg, Cuxhaven, Rotenburg (Wümme), Stade und Nordwestmecklenburg werden über $70 \%$ der Bodenfläche landwirtschaftlich genutzt.

Land- und Forstwirtschaft sind von der globalen bis zur regionalen Ebene stark mit dem Klimawandel verknüpft (- Abb. 7.1). Weltweit tragen sie durch die Emission von Spurengasen (insbesondere Methan und Distickstoffoxid) und die Freisetzung von $\mathrm{CO}_{2}$ infolge von Landnutzungsänderungen zur Erhöhung der Treibhausgaskonzentration der Atmosphäre bei und gelten als bedeutende Ursache des Klimawandels. Andererseits hat der Klimawandel durch den Temperaturanstieg, erhöhte $\mathrm{CO}_{2}$-Konzentrationen sowie veränderte Niederschlagsmuster und Extremwetterlagen direkte Auswirkungen auf die Land- und Forstwirtschaft, die sich den sich verändernden Umweltbedin-

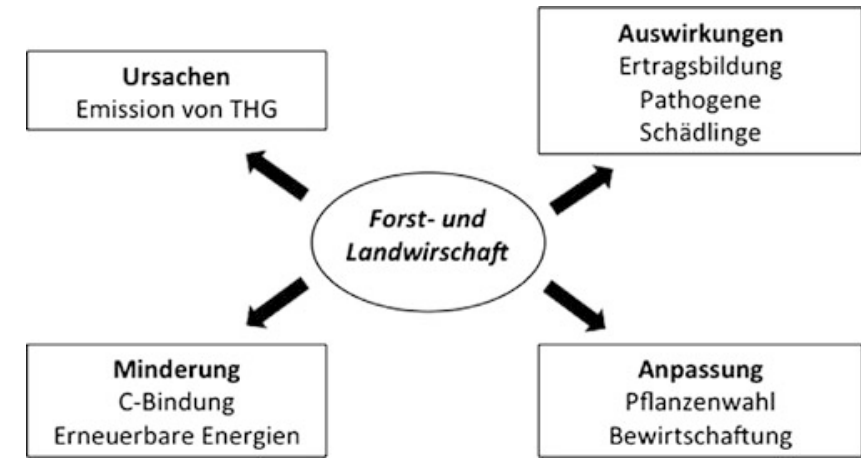

- Abb. 7.1 Land- und Forstwirtschaft im Klimawandel. (Nach Schaller und Weigel 2007)

gungen anpassen muss. Wie wirksam diese Anpassung erfolgen kann, hängt insbesondere für die Forstwirtschaft vom zeitlichen Verlauf des Klimawandels ab; aufgrund des hohen Lebensalters von Bäumen erfordert die natürliche Fähigkeit von Waldökosystemen zur Anpassung an veränderte Klimabedingungen lange Zeiträume (Otto 1994). Der rasche Fortschritt des anthropogen verursachten Klimawandels könnte die Anpassungsfähigkeit von 


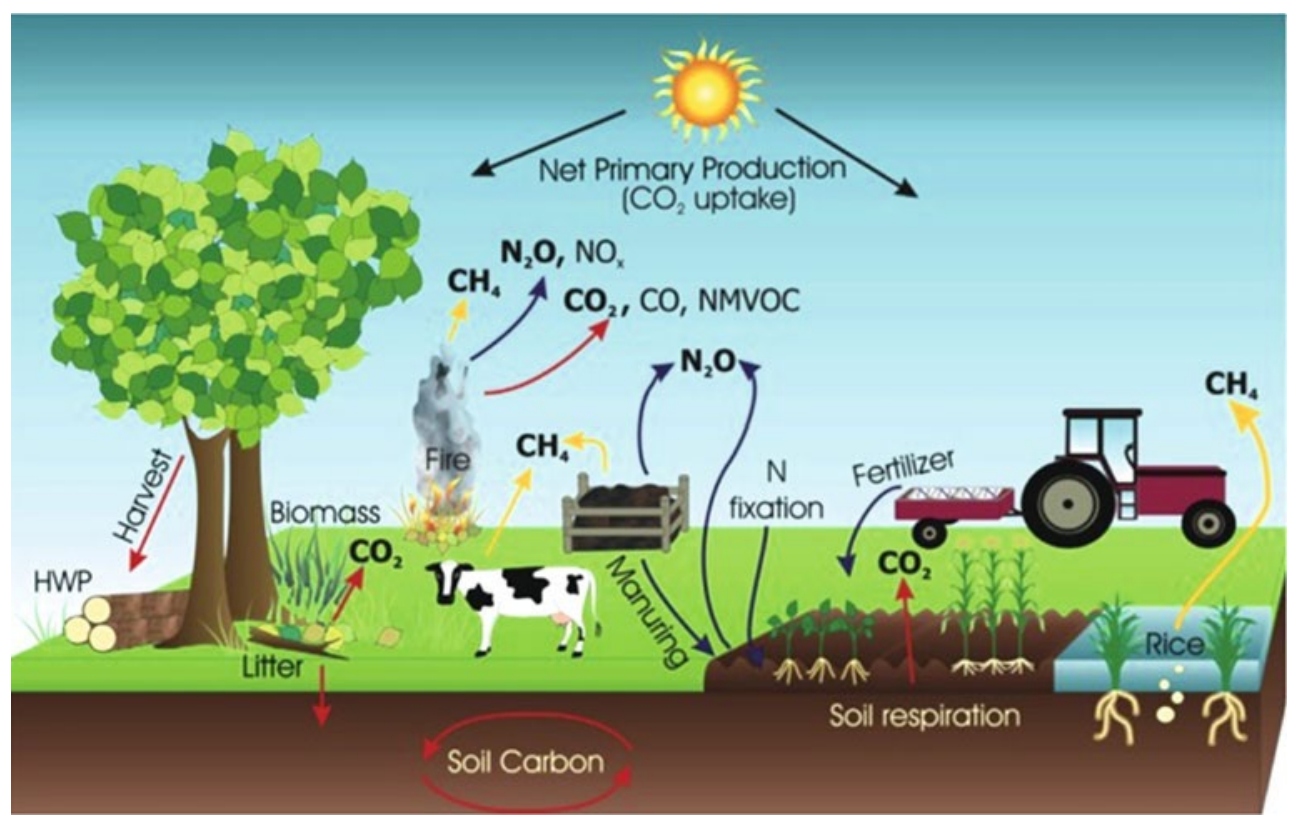

- Abb. 7.2 THG-Quellen in der Land- und Forstwirtschaft. (IPCC 2006)
Wäldern überfordern. Land- und insbesondere Forstwirtschaft tragen aber auch zu einer Minderung des Klimawandels bei. Pflanzen binden über die Photosynthese atmosphärisches $\mathrm{CO}_{2}$ und wirken somit als Kohlenstoffsenke. Durch Extensivierungsmaßnahmen, insbesondere durch ökologische Landwirtschaft, kann der Ausstoß von klimaschädlichen Treibhausgasen (THG) pro Flächeneinheit ${ }^{1}$ verringert werden. Der Anbau von nachwachsenden Rohstoffen trägt zur Verringerung der THG-Emissionen durch den Ersatz fossiler Energiequellen bei.

Die Wahl von Anpassungs- und Minderungsmaßnahmen ist nicht frei von Zielkonflikten. So werden Entscheidungen zum Anbau klimaangepasster Sorten, zur Erhöhung des Kohlenstoffspeichers von Wäldern durch Nutzungsverzicht oder zum Anbau von nachwachsenden Rohstoffen statt Lebensmitteln kontrovers und häufig nicht ideologiefrei diskutiert (z. B. Sachverständigenrat Umwelt 2012; Erler et al. 2012; Graham-Rowe 2012).

\subsubsection{Land- und Forstwirtschaft als Ursache des Klimawandels}

Die Landwirtschaft trägt 10-11 \% (IPCC 2014) zu den globalen THG-Emissionen bei, Entwaldung, Walddegradierung, Waldund Torffeuer und die Zersetzung von organischem Kohlenstoff in drainierten Moorböden weitere 10-20 \% (van der Werf et al. 2009; Harris et al. 2012; Tubiello et al. 2014). Im Zeitraum 2004-2013 wurden jährlich durchschnittlich 0,9 \pm 0,5 GtC durch Landnutzungsänderungen freigesetzt (Le Quéré et al. 2015). 2008 führte das globale Ernährungssystem einschließlich Produktion, Düngemittelherstellung, Kühlung und Emissionen aus Entwaldung und Landnutzungsänderungen zur Freisetzung von 980016.900 $\mathrm{Mt} \mathrm{CO}_{2 \mathrm{e}}$ (Vermeulen et al. 2012).

1 Produktbezogene Emissionen sind bei konventioneller Landwirtschaft geringer, Abschn. 7.2.3
Auch in Deutschland trägt die Landwirtschaft zur Emission von THG bei. Im Jahr 2013 war die Landwirtschaft für 6,7 \% (i. e. 64 Mio. $\mathrm{t}_{2 \mathrm{e}}$ ) der gesamten THG-Emissionen Deutschlands verantwortlich und ist damit nach den Emissionen aus stationärer und mobiler Verbrennung der zweitgrößte Verursacher von THG-Emissionen. Die wichtigsten Quellen der globalen THGEmissionen sind Viehhaltung, landwirtschaftlich genutzte Böden sowie der Einsatz von Düngemitteln und Pestiziden (Schaller und Weigel 2007; IPCC 2014; Umweltbundesamt 2014). Der Maschineneinsatz in der Landwirtschaft führt im Vergleich zum Verkehrssektor zu vernachlässigbaren Emissionen (Schaller und Weigel 2007). 2013 verursachte die Landwirtschaft rund $54 \%$ der Methanemissionen und 77 \% der Lachgasemissionen in Deutschland (Umweltbundesamt 2014).

- Abb. 7.2 zeigt eine globale Übersicht der THG-Quellen der Land- und Forstwirtschaft. Die wichtigsten Quellen von THG-Emissionen aus der Landwirtschaft sind Emissionen von Methan $\left(\mathrm{CH}_{4}\right)$ sowie Lachgas (Distickstoffoxid, $\mathrm{N}_{2} \mathrm{O}$ ) und seine Vorläufersubstanzen (Stickoxide, $\mathrm{NO}_{\mathrm{x}}$; Stickstoff, $\mathrm{N}_{2}$ ). Das klimawirksame Spurengas Methan entsteht durch das Wirtschaftsdüngermanagement (Festmist und Gülle) sowie die enterogene Fermentation im Pansen von Wiederkäuern (Schafe, Rinder). 2013 trug die Lagerung und Ausbringung von Festmist und Gülle rund $20 \%$ zu den gesamten Methanemissionen der deutschen Landwirtschaft bei (Umweltbundesamt 2014), wovon ein Großteil auf die Exkremente von Rindern und in geringerem Umfang von Schweinen zurückgeht. Die entsprechenden Beiträge von anderen Tiergruppen sind vernachlässigbar. Emissionen von Lachgas und seinen Vorläufersubstanzen entstehen vor allem aus umgewidmeten Mooren und Grünland, gedüngten und ungedüngten Ackerkulturen sowie in geringerem Umfang aus Festmist, der bei der Einstreuhaltung anfällt.

In der MRH haben sich zwischen 2009 und 2014 die Rinderbestände leicht erhöht ( $\bullet$ Tab. 7.3). Gleiches trifft für den Bestand der Milchkühe zu. Legt man den deutschen Rinderbestand 
- Tab. 7.3 Bestand Rinder und Milchkühe 2009 und 2014. (Statistische Ämter des Bundes und der Länder 2015)

\begin{tabular}{|c|c|c|c|c|}
\hline & \multicolumn{2}{|c|}{ Rinder insgesamt } & \multicolumn{2}{|l|}{ Milchkühe } \\
\hline & Anzahl 2009 & Anzahl 2014 & Anzahl 2009 & Anzahl 2014 \\
\hline Lübeck & 2736 & 2478 & 870 & 815 \\
\hline Neumünster & 2329 & 3104 & 825 & 1038 \\
\hline Dithmarschen & 137.552 & 135.335 & 36.972 & 41.312 \\
\hline Herzogtum Lauenburg & 30.557 & 30.300 & 8469 & 8857 \\
\hline Ostholstein & 25.132 & 25.122 & 8606 & 8824 \\
\hline Pinneberg & 47.911 & 47.235 & 15.120 & 16.855 \\
\hline Segeberg & 73.024 & 70.548 & 24.145 & 25.018 \\
\hline Steinburg & 126.524 & 124.219 & 42.962 & 46.122 \\
\hline Stormarn & 26.944 & 28.475 & 9997 & 10.849 \\
\hline Hamburg & 6436 & 6283 & 1053 & 1152 \\
\hline Cuxhaven & 282.156 & 283.564 & 99.249 & 110.246 \\
\hline Harburg & 36.873 & 39.914 & 10.956 & 13.650 \\
\hline Lüchow-Dannenberg & 22.821 & 22.757 & 6675 & 6524 \\
\hline Lüneburg & 30.485 & 31.292 & 10.671 & 11.137 \\
\hline Rotenburg (Wümme) & 177.899 & 179.924 & 57.731 & 65.264 \\
\hline Heidekreis & 39.309 & 39.953 & 11.052 & 12.447 \\
\hline Stade & 106.437 & 112.371 & 39.066 & 45.124 \\
\hline Uelzen & 12.999 & 13.166 & 3909 & 4078 \\
\hline Nordwestmecklenburg & 45.698 & 49.112 & 20.387 & - \\
\hline Ludwigslust-Parchim & - & 136.239 & - & 51.159 \\
\hline Ludwigslust & 72.436 & - & 23.420 & - \\
\hline Insgesamt & 1.306 .258 & 1.381.391 & 432.135 & 480.471 \\
\hline
\end{tabular}

(Statistische Ämter des Bundes und der Länder 2015) und die Emissionen aus der Tierhaltung (Umweltbundesamt 2014) für eine überschlägige Berechnung zugrunde, führte der Tierbestand in der MRH 2014 zu Emissionen von schätzungsweise 4,1 Mio. Mt $\mathrm{CO}_{2 \mathrm{e}}$. Dieser Wert entspricht etwa $6 \%$ der Emissionen der gesamten deutschen Landwirtschaft.

Neben der Tierhaltung sind auch landwirtschaftlich genutzte Böden eine Quelle von klimarelevanten Gasen. Hierbei handelt es sich hauptsächlich um Lachgasemissionen sowie erhöhte $\mathrm{CO}_{2}$-Freisetzungen durch den Umbruch von Grünland- und Moorstandorten. Lachgasemissionen entstehen durch die mikrobakterielle Umwandlung von Stickstoffverbindungen in Böden und werden in direkte und indirekte Emissionen unterschieden. Direkte Lachgasemissionen entstehen durch die Landwirtschaft selbst, indem Nährstoffe umgesetzt werden, die durch Weidegang, Wirtschaftsdünger, Mineraldüngen und Klärschlamm, biologische Stickstofffixierung durch Leguminosen, die Zersetzung von Ernterückständen und Bewirtschaftung organischer Böden ausgebracht bzw. gebunden wurden. Nach FAO (FAOSTAT 2014) stiegen zwischen 1961 und 2010 die Emissionen, die auf die An- wendung synthetischer Dünger zurückzuführen sind, weltweit um 900 \%. Ein Kilogramm Düngemittel führt nach Schaller und Weigel (2007) zur Freisetzung von ca. $10 \mathrm{~kg} \mathrm{CO}_{2 \mathrm{e}}$.

Indirekte Lachgasemissionen sind eine Folge von Depositionen reaktiven Stickstoffs sowie Auswaschungen und Oberflächenabfluss auf gedüngten Böden. Letztere wirken sich vor allem auf den Nährstoffhaushalt von naturnahen oder natürlichen Ökosystemen aus. Zwischen 1990 und 2012 sind die Lachgasemissionen aus Böden deutschlandweit um rund $14 \%$ zurückgegangen und betrugen 2012 rund $94 \%$ der gesamten Lachgasemissionen der deutschen Landwirtschaft (Umweltbundesamt 2014). Für die MRH weist der Nationale Treibhausgasbericht (Umweltbundesamt 2014) keine Zahlen aus.

In Deutschland spielen THG-Emissionen durch Landnutzungsänderungen und nichtnachhaltige Waldnutzung eine vernachlässigbare Rolle. Wie in den übrigen Wäldern Deutschlands übersteigt auch in der MRH der Holzzuwachs die Holznutzung, sodass sich der Kohlenstoffspeicher des Waldes in einem kontinuierlichen Aufbauprozess befindet. Auch findet keine $\mathrm{CO}_{2}$ Freisetzung durch großflächige Waldbrände statt. Zwischen 2011 
und 2014 waren in Niedersachsen, Schleswig-Holstein, Mecklenburg-Vorpommern und Hamburg zwischen 12 ha (2014) und 33 ha (2011) von Waldbränden betroffen (BLE 2015). Somit stellt die Forstwirtschaft im Gegensatz zur Landwirtschaft in der MRH keine Ursache des Klimawandels dar.

\subsubsection{Auswirkungen des Klimawandels auf die Land- und Forstwirtschaft}

Der Klimawandel hat gemäß OECD (2002) agronomische, sozioökonomische und ökologische Auswirkungen auf die Landwirtschaft. Die agronomischen Auswirkungen betreffen u. a. Änderungen der Standortfaktoren und deren Konsequenzen für den Anbau von Kulturpflanzen und die Tierhaltung, Pflanzenschutzmaßnahmen durch veränderte Ausbreitungsmuster und Virulenz von Pathogenen und Krankheiten, zunehmenden Bewässerungsbedarf sowie Veränderungen der Bodenfruchtbarkeit. Umweltauswirkungen entstehen durch den Verlust an Biodiversität, die Belastung von natürlichen und naturnahen Ökosystemen durch den erhöhten Einsatz von Düngemitteln und Pestiziden oder die Beeinflussung der Wasserverfügbarkeit infolge von landwirtschaftlichen Bewässerungsmaßnahmen. Zudem kann der Klimawandel zu Ertrags- und damit Gewinneinbußen führen und das Risiko der landwirtschaftlichen Produktion erhöhen.

Der Faktorenkomplex aus Klima, Boden und Wasserverfügbarkeit bestimmt das natürliche Vorkommen von Baumarten. Mit zunehmender Wärme und länger anhaltenden Trockenperioden im Sommer können Bäume in Hitze- und Trockenstress geraten; das Wachstum und die Vitalität von Wäldern werden negativ beeinflusst. Die Folge wären Ertragseinbußen und eine geringere Kohlenstoffsequestrierung. Zudem steigt durch mildere Winter sowie wärmere und trockenere Sommer das Risiko von Schädlingskalamitäten, z. B. durch Borkenkäfer, und Waldbränden.

Im Folgenden werden die Auswirkungen des Klimawandels auf die Land- und Forstwirtschaft im Hinblick auf veränderte Temperatur- und Niederschlagsverhältnisse, auf das Pflanzenwachstum durch gesteigerte $\mathrm{CO}_{2}$-Konzentrationen und auf die Entwicklung von Schaderregern und Pflanzenkrankheiten dargestellt.

\subsubsection{Standortfaktoren Temperatur und Niederschlag}

Jährliche Klimavariabilität ist eine der Hauptursachen für schwankende Erträge und das inhärente Risiko der landwirtschaftlichen Produktion. Zur Beurteilung der Auswirkungen des Klimawandels auf das Pflanzenwachstum müssen die Klimafaktoren und der Witterungsverlauf im Zusammenhang mit den Standortansprüchen der einzelnen Pflanzenarten betrachtet werden. In 0 Tab. 7.4 sind beispielhaft Einflüsse von Temperatur und Niederschlag auf einzelne Komponenten des Agrarökosystems dargestellt.

Für die Land- und Forstwirtschaft sind neben Temperaturänderungen vor allem die Höhe und die jahreszeitliche Verteilung der Niederschläge von Bedeutung. In den letzten 100 Jahren wurden in der MRH ein Anstieg der Jahresmitteltemperaturen um etwa $1{ }^{\circ} \mathrm{C}$ und eine Zunahme der Jahresniederschlagshöhe beobachtet. Gehölze der gemäßigten Breiten können kurzfristige Maximaltemperaturen zwischen 45 und $55^{\circ} \mathrm{C}$ ohne irreversible
- Tab. 7.4 Einfluss von Lufttemperatur und Niederschlag auf einzelne Komponenten des Agrarökosystems. (Nach Olesen und Bindi 2004)

\begin{tabular}{|c|c|c|}
\hline Komponente & Temperatur & Niederschlag \\
\hline Pflanzen & $\begin{array}{l}\text { Länge der Wachstumspe- } \\
\text { riode }\end{array}$ & $\begin{array}{l}\text { Trockenmasse- } \\
\text { produktion }\end{array}$ \\
\hline Tiere & $\begin{array}{l}\text { Wachstum und Reproduk- } \\
\text { tion }\end{array}$ & Gesundheit \\
\hline Wasser & $\begin{array}{l}\text { Bewässerungsbedarf } \\
\text { Versalzung }\end{array}$ & Grundwasser \\
\hline Böden & $\begin{array}{l}\text { Umsatz organischer Sub- } \\
\text { stanz } \\
\text { Nährstoffversorgung }\end{array}$ & $\begin{array}{l}\text { Erosion } \\
\text { Pflanzenverfüg- } \\
\text { bares Wasser }\end{array}$ \\
\hline $\begin{array}{l}\text { Schädlinge } \\
\text { und Krank- } \\
\text { heiten }\end{array}$ & $\begin{array}{l}\text { Generationszeit } \\
\text { Frühe des Befalls }\end{array}$ & $\begin{array}{l}\text { Populationsdy- } \\
\text { namik } \\
\text { Krankheitsüber- } \\
\text { tragung }\end{array}$ \\
\hline Unkräuter & Wirksamkeit von Herbiziden & \\
\hline
\end{tabular}

Schäden überstehen (Tesche 1992). Das Zusammenspiel von Niederschlag, Wasserhaltekapazität des Bodens und Verdunstung ist entscheidend für eine ausreichende Wasserversorgung der Pflanzen. Niederschlagsmangel und eine durch hohe Temperaturen gesteigerte Verdunstung führen dazu, dass der Wassergehalt des Bodens absinkt und Pflanzen unter Wassermangel leiden (Otto 1994; Matyssek et al. 2010; Chmielewski 2011a). Durch den Wassermangel vermindert sich zunächst das Volumen der Pflanzenzelle, gefolgt von einer Erhöhung der Zellsaftkonzentration und einer Entquellung des Protoplasmas. Infolge des zurückgehenden Turgordrucks (i. e. Druck des Zellsafts auf die umgebende Zellwand) und eine damit einhergehende Veränderung des osmotischen Wertes in der Zelle wird zunächst das Wachstum verlangsamt. Trockenschäden entstehen, sobald das Wurzelwachstum eingestellt wird. Biomembranläsionen und der Zusammenbruch der Energieversorgung der Pflanzen führen anschließend zum Hitzetod (Roloff und Grundmann 2008).

Die Tendenz zu trockeneren Sommern wirkt sich auf die Landund Forstwirtschaft stärker aus als die deutliche Zunahme der Niederschläge im Herbst und Winter. Klimaszenarien legen nahe, dass sich die bisherige Tendenz zu höheren Temperaturen und trockeneren Sommern auch in Zukunft fortsetzt ( Abschn. 2.4), was zu einer Verschlechterung der Wachstums- und Produktionsbedingungen der Forst- und Landwirtschaft führen würde.

In den letzten Jahrzehnten haben sich die Vegetationsperioden verlängert, was durch Untersuchungen von phänologischen Daten belegt werden konnte (Menzel und Fabian 1999; Chmielewski und Rötzer 2001; Bissolli et al. 2005). So setzen im Jahresverlauf Laubaustrieb oder Blüte deutlich früher ein, Laubverfärbung und Laubwurf nur unwesentlich später. Längere Vegetationsperioden können zu einer Erhöhung der Biomasseproduktion führen. Sie können sich aber auch negativ auf die Wechselwirkungen zwischen Arten z. B. bei der Bestäubung auswirken (Menzel et al. 2006; Thomson 2010). Die Frosthärte von Bäumen wird durch milde Winter verringert und kann so zu einer Zunahme von Spätfrostschäden führen. Durch wärmere Episoden im Winter kann der Stoffwechsel von Bäumen während 
- Tab. 7.5 Feldfruchtarten Hektarerträge (dt/ha), 2013. (Statistische Ämter des Bundes und der Länder 2015)

\begin{tabular}{|c|c|c|c|c|c|c|c|c|c|c|}
\hline & $\begin{array}{l}\text { Winter- } \\
\text { weizen }\end{array}$ & $\begin{array}{l}\text { Roggen } \\
\text { und Win- } \\
\text { termeng- } \\
\text { getreide }\end{array}$ & $\begin{array}{l}\text { Winter- } \\
\text { gerste }\end{array}$ & $\begin{array}{l}\text { Sommer- } \\
\text { gerste }\end{array}$ & Hafer & Triticale & Kartoffeln & $\begin{array}{l}\text { Zucker- } \\
\text { rüben }\end{array}$ & $\begin{array}{l}\text { Winter- } \\
\text { raps }\end{array}$ & Silomais \\
\hline Lübeck & 87,9 & 84,6 & 86,4 & 0 & 0 & 0 & 0 & 680 & 42,9 & 375,8 \\
\hline Neumünster & 78,6 & 79,6 & 76,4 & 0 & 0 & 0 & 0 & 600 & 47 & 444,8 \\
\hline Dithmarschen & 86,9 & 76,5 & 85,4 & 0 & 0 & 0 & 0 & 713,2 & 40,2 & 389,7 \\
\hline Herzogtum Lauenburg & 91,6 & 75,7 & 85,7 & 0 & 0 & 0 & 0 & 640,6 & 41,3 & 369,9 \\
\hline Ostholstein & 98,1 & 75,5 & 93,3 & 0 & 0 & 0 & 0 & 657,3 & 44 & 389,4 \\
\hline Pinneberg & 83,1 & 71,6 & 78,7 & 0 & 0 & 0 & 0 & 0 & 37,8 & 373,4 \\
\hline Segeberg & 87,1 & 80,3 & 83,2 & 0 & 0 & 0 & 0 & 606,1 & 40,4 & 376,3 \\
\hline Steinburg & 81,6 & 75,6 & 80,4 & 0 & 0 & 0 & 0 & 630,9 & 38,3 & 383 \\
\hline Stormarn & 88,5 & 81,4 & 80,5 & 0 & 0 & 0 & 0 & 680 & 40,1 & 380,9 \\
\hline Hamburg & - & - & - & - & - & - & - & - & - & - \\
\hline Cuxhaven & 82,6 & 69,6 & 70,7 & 59,7 & 52,9 & 68,8 & 422,8 & 645,3 & 40,4 & 405,3 \\
\hline Harburg & 80,9 & 66,8 & 67,9 & 59,2 & 50,5 & 68,4 & 429,9 & 646 & 38,5 & 388,5 \\
\hline Lüchow-Dannenberg & 80,8 & 68,9 & 71,5 & 60,7 & 52,3 & 69,5 & 449,5 & 657,1 & 39,6 & 411,8 \\
\hline Lüneburg & 79,6 & 72,6 & 70,5 & 59,5 & 50,7 & 71,3 & 429,3 & 638,3 & 38,9 & 382 \\
\hline Rotenburg & 78,8 & 73,5 & 67,9 & 59,6 & 46,8 & 68,6 & 431,1 & 641,2 & 37,9 & 387,9 \\
\hline Heidekreis & 80,6 & 70,4 & 68,7 & 60,8 & 48,3 & 69 & 434,2 & 644 & 38,2 & 393,5 \\
\hline Stade & 82,2 & 73,7 & 72 & 60,1 & 54,3 & 72,2 & 447,9 & 642,2 & 39,4 & 414,4 \\
\hline Uelzen & 85,5 & 72,5 & 73,8 & 61,6 & 52,5 & 71 & 447 & 637,6 & 40,5 & 400,8 \\
\hline Nordwestmecklenburg & 90,4 & 70 & 84,3 & 53,2 & 54,5 & 69,9 & 334 & 624,7 & 42,9 & 330,5 \\
\hline Ludwigslust-Parchim & 78,2 & 60,5 & 70,7 & 50,6 & 47,1 & 59 & 367,9 & 604,5 & 32,5 & 303,9 \\
\hline
\end{tabular}

der Winterruhe aktiviert werden und sich durch den damit hervorgerufenen physiologischen Stress negativ auf die Vitalität auswirken (Kätzel 2008). Auch Schadorganismen profitieren von längeren Vegetationszeiten, indem $u$. a. ihre Populationsgröße durch die Ausbildung zusätzlicher Generationen zunimmt.

Die Nähe zu Nord- und Ostsee prägt das Klima der MRH. Dies führt zu einem wechselhaften Wettercharakter mit nur mäßig warmen Sommern und relativ milden Wintern. Bei Ostwinden dringen kontinentale Luftmassen in die MRH vor. Mit zunehmendem Abstand zu den Küsten nimmt die Kontinentalität des Klimas zu. Der südöstliche Teil der MRH weist im Jahresmittel etwas höhere Temperaturen auf. Besonders die Landkreise Lüneburg, Lüchow-Dannenberg und Uelzen sind im Vergleich zur restlichen MRH trockener (von Storch und Claussen 2011).

Die im Vergleich zum Bundesdurchschnitt kühleren Sommer sowie die relativ gute Niederschlagsversorgung führen in der MRH zu Spitzenerträgen bei verschiedenen Feldfruchtarten, wie Winterweizen, Wintergerste, Roggen oder Raps, sowie im Grünlandbau (Schaller und Weigel 2007; Chmielewski 2011b). - Tab. 7.5 zeigt die Hektarerträge (dt/ha) der wichtigsten Feldfruchtarten in den Kreisen der MRH. Unterschiede sind hierbei aber nicht nur auf die unterschiedlichen klimatischen Bedingungen, sondern auch auf Düngemitteleinsatz, Anbaumethoden und vor allem auf die Bodeneigenschaften zurückzuführen.
Veränderte Temperatur- und Niederschlagsverhältnisse zu verschiedenen Zeitpunkten der Vegetationsperiode werden sich auf einzelne Kulturpflanzen unterschiedlich stark auswirken. Unter den Getreidearten stellt Weizen die höchsten Ansprüche an die klimatischen Bedingungen. Er verlangt wintermilde und sommerwarme Klimate mit hoher Strahlungsintensität sowie eine ausreichende Wasserversorgung während der Vegetationszeit. Der Transpirationskoeffizient von 500 Litern Wasser pro kg Trockenmasse zeigt den hohen Wasserverbrauch von Weizen. Wassermangel in der Kornfüllungsphase kann zu einer deutlichen Reduzierung der Tausendkornmassen führen. Aber auch in der Zeit vom Schossen bis zur Blüte ist eine ausreichende Wasserversorgung essenziell. Ebenso ist die Temperatur entscheidend für die Weizenentwicklung. Milde Winter und kühle Frühjahrstemperaturen fördern die Entwicklung von Winterweizen. Während der Reifephase wirkt sich Hitze negativ auf die Ausbildung der Korngröße und des Einzelkorngewichts aus (Chmielewski und Köhn 2000). Die Ertragseinbußen, die während des Hitzesommers 2003 beobachtet wurden, geben einen Hinweis auf die Auswirkungen des zukünftigen Klimawandels (Schaller und Weigel 2007).

Wintergerste ist weniger hitzeempfindlich als Winterweizen. Die Begrannung gewährleistet eine Abkühlung der Ähren durch Verdunstung, sofern genügend Wasser aus dem Boden verfügbar ist. Im Vergleich zu Winterweizen ist der Wasserverbrauch 
der Gerste geringer, da ein größerer Teil der vegetativen Entwicklung bereits im Herbst und Winter erfolgt. In SchleswigHolstein werden deutschlandweit die höchsten Erträge erzielt (Schaller und Weigel 2007; Statistische Ämter des Bundes und der Länder 2015). Anhand von Dauerfeldversuchen konnte gezeigt werden, dass Klimafaktoren einen Großteil der Ertragsvariabilität von Winterroggen und Sommergetreide erklären können (Chmielewski und Köhn 1999, 2000). Franzaring et al. (2007) verknüpften historische Ertragsstatistiken mit Daten zu Strahlung, Niederschlag, Temperatur und Konzentration atmosphärischer Verbindungen. Für Südwestdeutschland fanden sie starke negative Korrelationen zwischen Sommertemperaturen und Ernteerträgen. Daten der 1990er-Jahre zeigen, dass für jedes Grad Temperatursteigerung die Erträge um 5-10 \% sinken. Die Auswirkungen von steigenden Sommertemperaturen auf die Ernteerträge müssen aber auch im Hinblick auf die Wasserversorgung der Pflanzen diskutiert werden (Chmielewski 2011a).

Durch das maritim geprägte Klima ist die $\mathrm{MRH}$ ein bevorzugter Standort für Dauergrünland. In Hamburg entfällt mit etwa 6800 ha der größte Teil der landwirtschaftlich genutzten Fläche auf Dauergrünland (Bürgerschaft der Freien und Hansestadt Hamburg 2014). Die Zusammensetzung der Pflanzengesellschaften auf Dauergrünland variiert mit den klimatischen Bedingungen und der Nutzung als Weide oder Mahd. Warme Temperaturen im Frühjahr und feuchte Sommer führen zu Höchsterträgen. In trockenen Sommern sind Ertragseinbußen zu erwarten.

In der MRH spielt der Anbau von Obst und Gemüse eine besondere Rolle. Das „Alte Land“ ist die nördlichste Obstanbauregion Deutschlands und erstreckt sich auf einer Fläche von rund 10.000 ha. Auf rund 88 \% der Fläche werden Äpfel angebaut, gefolgt von Süßkirschen (5\%), Birnen (3\%), Pflaumen (1,6 \%) und Sauerkirschen (1 \%) (Keckl 2005; Chmielewski 2011b). Die am häufigsten angebauten Apfelsorten sind Elstar und Jonagold, wobei die Sortenwahl einen deutlichen Einfluss auf den jährlichen Ertrag, die Lagerfähigkeit und den Preis hat (Keckl 2005). Qualität und Quantität der Produktion hängen in hohem Maße von der Witterung im Erntejahr ab und sind daher starken Schwankungen unterworfen. Der beobachtete Temperaturanstieg hat bereits zu einem deutlich früheren Blühbeginn von Obstgehölzen geführt (Chmielewski et al. 2004). Im Alten Land blühen die Obstgehölze seit 1975 um wenigstens zwei Wochen verfrüht (Chmielewski 2011b). Mit dem früheren Blühbeginn werden sich auch die Erntezeiten zu einem früheren Termin hin verschieben. Ebenso kann die Gefahr von Spätfrostschäden zunehmen, die aber an der Niederelbe im Vergleich zu weiter südlich im Landesinnern gelegenen Anbaugebieten nur gering steigen wird.

Neben Temperatur und Niederschlag während der Vegetationsperiode wirken sich auch die Temperaturen im Winterhalbjahr auf die Obstproduktion aus. Obstgehölze müssen über einen längeren Zeitraum kühleren Temperaturen zwischen ca. 3 und $10^{\circ} \mathrm{C}$ ausgesetzt sein, um vom vegetativen zum generativen $\mathrm{Zu}$ stand übergehen zu können. Um die Blütenbildung auszulösen, müssen diese niedrigen Temperaturen über eine bestimmte Zeitdauer einwirken. Gerade in den wintermilden nordwestlichen Regionen Deutschlands kann dieser Kältereiz, der zur Überwindung der Winterruhe unerlässlich ist, im Zuge des Klimawandels erst später erfüllt sein (Chmielewski et al. 2012). Zu hohe Herbstund Wintertemperaturen stören diesen Prozess und führen zu einem unregelmäßigen und verspäteten Blühbeginn.

Für die Landwirtschaft in der MRH können sich sowohl Chancen als auch Risiken durch den zu erwartenden Klimawandel ergeben. Konkrete Aussagen sind im Moment aufgrund fehlender Detailstudien noch nicht möglich und werden sich erst durch die zukünftigen Ergebnisse laufender Forschungsarbeiten treffen lassen. Die Wechselwirkungen zwischen Temperatur und Wasserverfügbarkeit werden aber einen entscheidenden Einfluss auf die zukünftigen Wachstumsbedingungen und Ertragspotenziale in der Landwirtschaft haben (Chmielewski 2011a).

Auch in der Forstwirtschaft werden höhere Temperaturen in Verbindung mit abnehmenden Niederschlägen in den Sommermonaten einen entscheidenden Einfluss auf die Vitalität von Bäumen haben. Das natürliche Verbreitungsgebiet von Bäumen wird u. a. von ihrer Hitze- und Trockenheitsresistenz sowie ihrer Frostresistenz beeinflusst. Die Frostresistenz kann in Deutschland bei zukünftigen Änderungen des Temperaturregimes vor allem in höheren Lagen entscheidend für die Verbreitung von Baumarten sein, spielt aber in der MRH ebenso wie die Hitzeresistenz eine eher untergeordnete Rolle. Hier wird vor allem die Trockenheitsresistenz Einfluss auf die zukünftige Baumartenverteilung und die Anbaueignung haben.

Bäume haben im Laufe ihrer Phylogenese Strategien zur Überdauerung von Trockenheitsperioden entwickelt. Hierzu zählen z. B. der vorzeitige Laubabwurf, die Reduktion der verdunstenden Flächen, das Schließen von Spaltöffnungen oder Wachsauflagen auf den Blättern. Bei der Beurteilung der Trockenheitsresistenz muss allerdings zwischen periodischen Ereignissen und langfristigen Veränderungen von Klimamustern unterschieden werden. Während die meisten Baumarten periodische Ereignisse wie den trockenen Sommer im Jahr 2003 bis auf Wachstumsdepressionen unbeschadet überstehen, können sich langfristige Veränderungen auf das Ausbreitungsgebiet der Arten auswirken. Aufzeichnungen der natürlichen Verbreitung von Baumarten (Bohn und Neuhäusl 2003) und Klimadaten können zur Abschätzung der Verschiebung von physiologischen Grenzen und damit den Ausbreitungsgebieten einzelner Arten dienen.

Aus waldökologischer Sicht beeinflussen nicht nur physiologische Grenzen das Vorkommen einer Art. Die potenzielle Arealgrenze einer Art wird bestimmt durch die Kombination von Bodeneigenschaften und Klima. Allerdings wirkt sich auf das potenzielle Verbreitungsareal auch die Konkurrenz anderer Arten aus. So können einzelne Arten von Standorten, die ihren physiologischen Ansprüchen genügen, durch die starke Konkurrenz anderer Arten verdrängt werden. In Mitteleuropa kommt die Kiefer aufgrund ihrer geringen Konkurrenzkraft nur auf Extremstandorten vor, die für konkurrenzstarke Baumarten wie die Buche nicht geeignet sind (Bolte et al. 2008). Daher kann sich das reale vom potenziellen Verbreitungsareal unterscheiden (Otto 1994; Ellenberg 1996). Im Zuge von Klimaveränderungen werden sich nicht nur die Standortbedingungen, sondern auch die Konkurrenzbeziehungen zwischen den Arten verändern. Eine Beurteilung veränderter Verbreitungsareale, die sich ausschließlich auf die Betrachtung sog. bioklimatischer Hüllen 
- Abb. 7.3 Baumartenverteilung in der MRH in Prozent der Biomasse. (Quelle: Bundeswaldinventur; eigene Berechnungen)

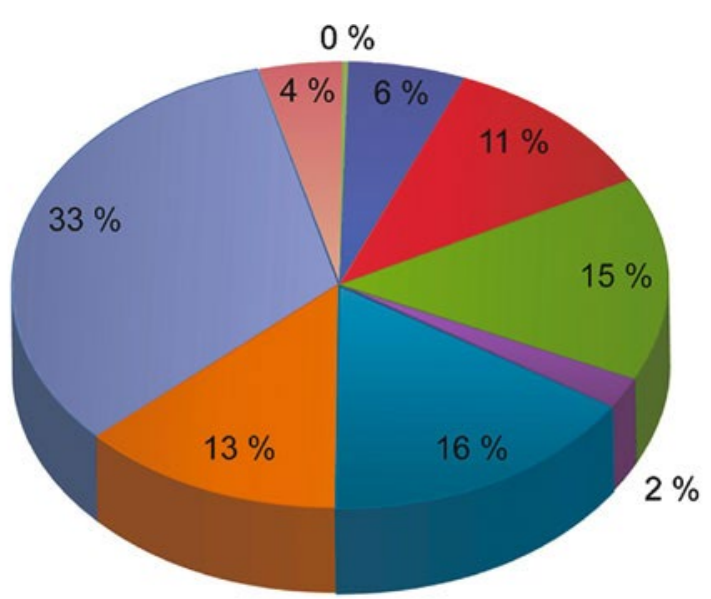

Anderes Laubholz hohes Lebensalter

Buche

Eiche

Kiefer

Tanne
(Klimahüllen, „bioclimatic envelopes“) bezieht (Bakkenes et al. 2002; Kölling 2007), ist daher kritisch zu bewerten (Bolte et al. 2008).

In der MRH sind gemessen am Anteil der Biomasse Kiefer (33,3 \%), Eiche (15,5\%), Buche (15,3 \%) und Fichte (13,3 \%) die häufigsten Baumarten ( $\bullet$ Abb. 7.3). Diese Baumarten sind im Hinblick auf ihre Reaktionen auf den Klimawandel unterschiedlich zu beurteilen.

Die Buche (Fagus sylvatica L.) ist die häufigste Laubbaumart Deutschlands und besonders gut an das ozeanische Klima angepasst. Sie findet sich bereits heute außerhalb ihres physiologischen Optimums. So wachsen Buchen im nordwestdeutschen Küstenraum auf nährstoffarmen und trockenen Dünensanden, obwohl diese Böden nicht zu ihren bevorzugten Standorten gehören (Otto 1994). Die Buche kann aufgrund ihrer hohen Trockenstresstoleranz auch trockene Phasen überstehen (Czajkowski et al. 2005; Czajkowski und Bolte 2006). Kriebitzsch et al. (2008) beschreiben die Wachstumsreaktionen von Buchen im Trockenjahr 2003 und in den darauffolgenden Jahren anhand eines Herkunftsversuchs, der Anfang der 1990er-Jahre in der Nähe von Kiel angelegt wurde. Sechs Buchenherkünfte, die von klimatisch sehr unterschiedlichen Standorten stammen (Brandenburg, Harz, Rumänien, Tschechien, Spanien und Österreich mit mittleren Jahresniederschlägen zwischen 575 und $1400 \mathrm{~mm}$ ) und im Freilandversuch unter gleichen Bedingungen angebaut werden, wurden in die Untersuchung eingeschlossen. Alle Herkünfte zeigten einen deutlichen Rückgang der Wachstumsraten im Trockensommer 2003, die Erholung der Zuwachsraten erfolgte aber sehr unterschiedlich. Bei einigen Herkünften konnte auch in den Folgejahren eine verringerte Spaltöffnungsweite und damit ein reduzierter Zuwachs beobachtet werden. Nach Kriebitzsch et al.
(2008) reagieren einige Herkünfte empfindlicher auf Klimastress und benötigen lange Erholungsphasen, sodass eine dichtere Abfolge von Trockenjahren zur Destabilisierung von Waldbeständen führen könnte.

Die Stieleiche (Quercus robur L.) findet optimale Wuchsbedingungen auf tiefgründigen, frischen bis feuchten Böden, gedeiht aber auch gut auf trockenen Böden. Sie verträgt sommerliche Trockenzeiten meist ohne Schaden. Die Traubeneiche (Quercus petraea (Matt.) Liebl.) bevorzugt mäßig sommertrockene und wintermilde Klimalagen. Sie hat geringere Ansprüche an die Bodenfeuchtigkeit und wächst auch auf sehr trockenen Standorten (Mayer 1999). Nach Roloff und Grundmann (2008) wird die Eiche vom Klimawandel wahrscheinlich am stärksten profitieren, da sie sich aufgrund ihrer tiefreichenden Pfahlwurzel zunehmend auf den Trockengebieten Norddeutschlands ausbreiten könnte. Von einem wärmeren Klima werden auch andere wärmetolerante Baumarten wie Hainbuche (Carpinus betulus L.) oder Sommerlinde (Tilia platyphyllos Scop.) profitieren.

In den Wäldern der MRH ist die Kiefer (Pinus sylvestris L.) die häufigste Baumart. Sie besitzt das höchste Ausbreitungsgebiet aller heimischen Baumarten, da sie eine hohe klimatische Anpassungsfähigkeit besitzt $\left(9-20^{\circ} \mathrm{C}\right.$ Sommertemperaturen, $400-$ $2500 \mathrm{~mm}$ Jahresniederschlag, 0 bis $-20^{\circ} \mathrm{C}$ Wintertemperatur) (Mayer 1999). Daher wird sie auch in Zukunft eine Hauptbaumart bleiben (Döbbeler und Spellmann 2002).

Die Fichte (Picea abies (L.) Karst.) gilt als der deutsche Problembaum, da sie über ein sehr schlechtes Anpassungspotenzial verfügt (Roloff und Grundmann 2008). Unter warm-trockenen Klimabedingungen kann die Fichte Wachstumsdepressionen und eine hohe Kalamitätsanfälligkeit sowie ein in höherem Alter zunehmendes Mortalitätsrisiko aufweisen (Schmidt-Vogt 1988). 
Im Trockensommer 2003 wurden bei der Fichte im Vergleich zu anderen Baumarten die größten Zuwachsrückgänge beobachtet (Fischer et al. 2006). In der MRH wächst die Fichte außerhalb ihres potenziellen Areals (Bohn und Neuhäusl 2003). Durch die Zunahme warm-trockener Sommer wird die MRH zu einem ungünstigen Standort für den Fichtenanbau werden.

Klimatische Veränderungen wirken sich nicht nur auf Bäume, sondern auch auf waldbewohnende nichtverholzende Pflanzenarten sowie Tierarten aus. Fischer et al. (2014) beschreiben erste Reaktionen auf Temperaturerhöhungen für Buchenwald-Lebensgemeinschaften in Bayern.

\subsubsection{2 $\mathrm{CO}_{2}$-Konzentration der Atmosphäre}

Seit der vorindustriellen Zeit ist der atmosphärische $\mathrm{CO}_{2}-\mathrm{Ge}$ halt von $280 \mathrm{ppm}$ auf heute etwa $404 \mathrm{ppm}$ angestiegen (Stand Mai 2015; Quelle: National Oceanic and Atmospheric Administration, Washington DC, USA). Die bisherige Dynamik in diesem Anstieg lässt erwarten, dass sich dieser $\mathrm{CO}_{2}$-Gehalt in den nächsten 100 Jahren sogar noch verdoppelt, falls in den nächsten Jahren keine einschneidenden gegensteuernden Maßnahmen getroffen werden sollten. Gegenwärtig wird, global gesehen, mehr $\mathrm{CO}_{2}$ aus der Verbrennung fossiler Energieträger sowie aus der großflächigen Vernichtung von Wäldern freigesetzt, als photosynthetisch in Biomasse gebunden wird. Fast ein Drittel der weltweit jährlich freigesetzten Kohlenstoffmenge wird von den Landpflanzen, vornehmlich Bäumen, als Nettozugewinn fixiert (Matyssek et al. 2010). Für die Pflanzen entsteht durch die rasante Zunahme des atmosphärischen $\mathrm{CO}_{2}$-Gehaltes eine ungewöhnliche Situation, da der über viele Millionen Jahre gebildete fossile Kohlenstoff in nur ca. 200 Jahren vom Menschen in die Atmosphäre emittiert wird. Die direkte Wirkung der $\mathrm{CO}_{2}$-Anreicherung auf Pflanzen, der sog. $\mathrm{CO}_{2}$-Düngeeffekt, wurde bereits in zahlreichen Experimenten untersucht. Es hat sich gezeigt, dass erdgeschichtlich jüngere C4Pflanzen wie z. B. Mais an relativ geringe $\mathrm{CO}_{2}$-Konzentrationen angepasst sind und bei einem ansteigenden $\mathrm{CO}_{2}$-Gehalt nicht mit einem Anstieg der Photosyntheserate reagieren. Eigene Versuche im Gewächshaus über eine Vegetationsperiode hinweg haben sogar gezeigt, dass Mais unter $950 \mathrm{ppm} \mathrm{CO}_{2}$ weniger Biomasse produziert als unter $400 \mathrm{ppm} \mathrm{CO}_{2}$. Dies bedeutet, dass erhöhte $\mathrm{CO}_{2}$-Konzentrationen unter Umständen sogar Wachstumsreduktionen hervorrufen können, auch wenn die biochemischen Wirkmechanismen hierfür noch nicht eindeutig geklärt sind. Bäume und die meisten landwirtschaftlichen Kulturpflanzen wie z. B. Getreide oder Hackfrüchte zählen jedoch zu den C3-Pflanzen, die erdgeschichtlich älter sind und sich dementsprechend auch an höhere $\mathrm{CO}_{2}$-Gehalte anpassen können. Wenn kein Mangel an Licht-, Wasser- und Nährstoffversorgung vorliegt, kann ein erhöhtes $\mathrm{CO}_{2}$-Angebot das Wachstum von C3-Pflanzen langfristig stimulieren, denn C3-Pflanzen können noch mit weit mehr $\mathrm{CO}_{2}$ als momentan in der Atmosphäre vorhanden auch mehr Photosynthese betreiben. Beispielsweise lässt sich hierzulande der Ertrag in einer Gewächshausgärtnerei um ca. 30 \% steigern, wenn die Pflanzen mit $\mathrm{CO}_{2}$-Konzentrationen von $600 \mathrm{ppm}$ und mehr begast werden. Auch im Freiland lassen sich bei ca. 600 ppm $\mathrm{CO}_{2}$ an Weizen und Reis Ertragssteigerungen von 7-12 \% erzielen, wenn die Felder ausreichend mit Wasser und Nährstoffen versorgt werden (Kimball et al. 2002). Im Freiland durchgeführte FACE-Versuche a

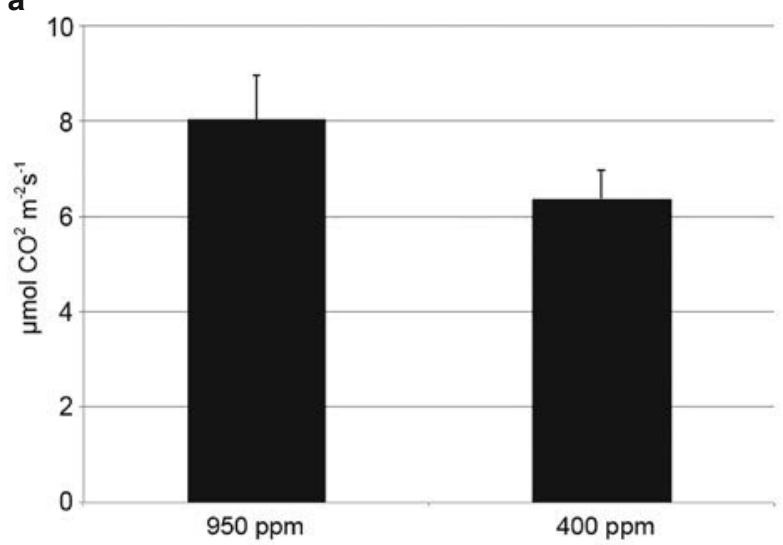

b

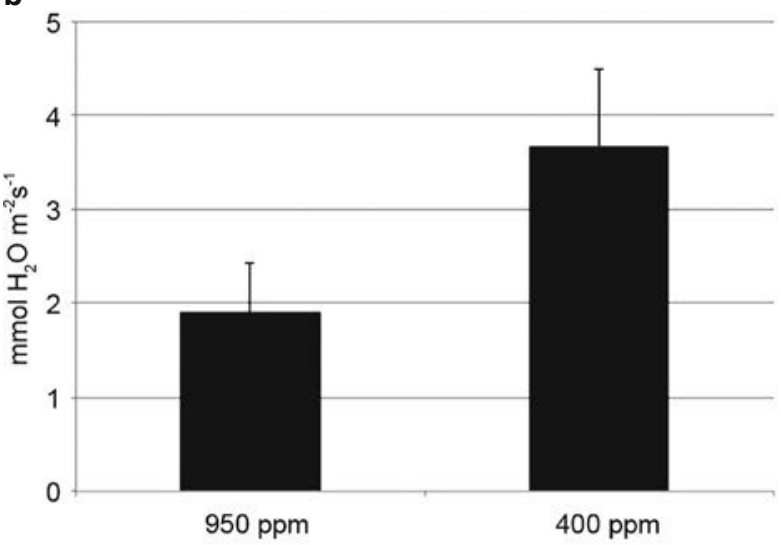

C

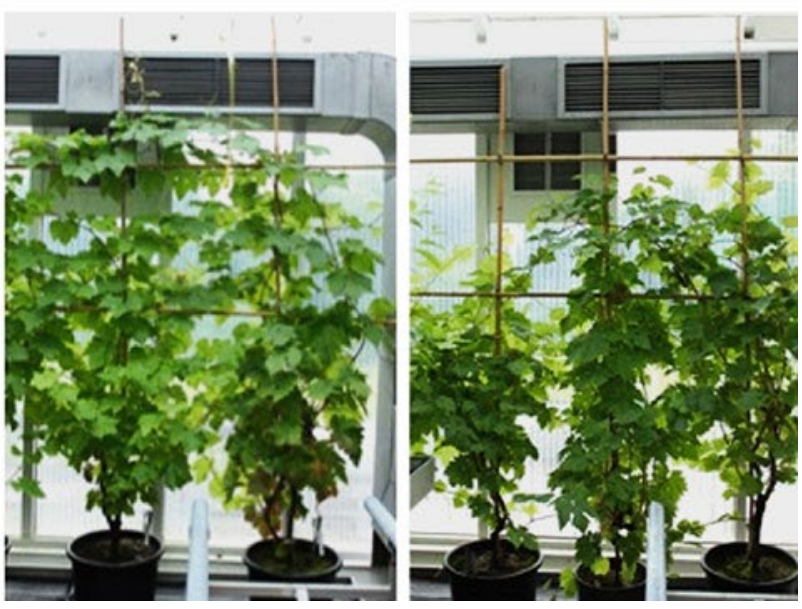

- Abb. 7.4 Wein: a. $\mathrm{CO}_{2}$-Aufnahmerate von Pflanzen unter 950 ppm sowie Kontrollbedingungen (400 ppm); b Transpirationsrate derselben Pflanzen unter 950 ppm sowie Kontrollbedingungen (400 ppm); c oberirdischer Biomassezuwachs unter 950 ppm (links) sowie unter Kontrollbedingungen (400 ppm, rechts). (Quelle: Gnoth 2015)

(„free air carbon enrichment“) unter 550 ppm $\mathrm{CO}_{2}$ zeigten bei landwirtschaftlichen Kulturpflanzen Ertragssteigerungen von etwa $10 \%$ (Weigel et al. 2006; Manderscheid und Weigel 2007).

Versuche mit Weinpflanzen im Gewächshaus haben z. B. gezeigt, dass bei einer Konzentration von 950 ppm $\mathrm{CO}_{2}$ die $\mathrm{CO}_{2}$ Aufnahmerate der Blätter deutlich zunimmt, wobei die Transpirationsrate sinkt, da die Öffnungsweite der Spaltöffnungen aufgrund des Überangebots an $\mathrm{CO}_{2}$ abnimmt (• Abb. 7.4a,b). Insgesamt betrachtet nimmt die Biomasse der Pflanzen aufgrund 
der erhöhten Photosynthese deutlich zu (• Abb. 7.4c). Aufgrund der erhöhten Photosynthese bei gleichzeitig verringerter Transpiration erhöht sich die Wassernutzungseffizienz, d. h., es wird mehr Trockenmasse pro Menge Transpirationswasser gebildet. Dadurch kann unter Normalbedingungen die Bodenfeuchte langsamer absinken. Auch können Pflanzen besser mit Trockenstress umgehen, der voraussichtlich im Rahmen des Klimawandels immer häufiger auftritt. Allerdings könnte bei älteren Beständen auch die Oberflächentemperatur aufgrund reduzierter Transpiration ansteigen. Die Rotbuche, eine der wichtigsten mitteleuropäischen Laubbaumarten, reagiert unter 950 ppm im Gewächshaus ähnlich wie Wein mit erhöhter Photosynthese und Anstieg der Biomasse, was sich auch in einer Zunahme der Jahrringbreite wiederspiegelt (Lotfiomran et al. 2015). Diese Versuche wurden jedoch an zweijährigen Bäumen durchgeführt und lassen sich nur schwer auf Altbestände übertragen. Eine langfristige Anpassung der Biomassezunahme an ein erhöhtes $\mathrm{CO}_{2}$-Angebot kann somit nicht ausgeschlossen werden. Dementsprechend haben Jahrringanalysen von in der Nähe geologischer $\mathrm{CO}_{2}$-Quellen wachsenden Steineichen (Quercus ilex) in der Toskana gezeigt, dass die Bäume nur in der Jugendphase (bis Alter 30) erhöhte Jahrringbreiten im Vergleich zu weiter entfernten Kontrollbäumen zeigen (Hättenschwiler et al. 1997). Jedoch ist klar erwiesen, dass Altbestände wesentlich mehr Kohlenstoff als junge Wälder speichern. Ein Ersatz von Altbeständen durch jüngere, auch wenn diese auf erhöhte $\mathrm{CO}_{2}$-Gehalte stärker reagieren, riefe somit einen Verlust der CSpeicherkapazität hervor. Zusätzliche Anpflanzungen von raschwüchsigen Kurzumtriebsplantagen wie z. B. durch Pappel oder Weide können aber fossile C-Quellen ersetzen und leisten somit einen wichtigen Beitrag zur Kohlenstoffentlastung der Atmosphäre. Wenn das Baumwachstum durch erhöhtes $\mathrm{CO}_{2}$ stimuliert wird, kommt es in vielen Fällen zunächst zu einer Steigerung der Kohlenstoffumsätze, z. B. durch schnelleren Feinwurzelumsatz oder C-Exporte an Mykorrhizapilze, bevor es zum Anstieg der Kohlenstoffvorräte im Baum kommt.

Zusammenfassend lässt sich festhalten, dass der Einfluss von $\mathrm{CO}_{2}$ auf das Pflanzenwachstum von der Pflanzenart und vom Alter der Pflanzen sowie von der Verfügbarkeit anderer Ressourcen abhängt. Verschiedene Arten können sehr unterschiedlich auf erhöhte $\mathrm{CO}_{2}$-Konzentrationen reagieren, sodass dadurch eine Verschiebung der natürlichen Wettbewerbsbedingungen erfolgen kann und sich langfristig somit die Artenzusammensetzung in den Ökosystemen verändern wird. Experimentelle Anordnungen von Freilandversuchen haben gezeigt, dass die Intensität, mit der Pflanzen auf $\mathrm{CO}_{2}$ reagieren, zudem auch wesentlich vom Pflanzenalter sowie von den Versuchsbedingungen und der Versuchsdauer abhängt (Hättenschwiler et al. 1997). Die Reaktion von Pflanzen auf $\mathrm{CO}_{2}$ hat sich unter optimaler Licht-, Wasser- und Nährstoffversorgung als am stärksten erwiesen. Nimmt aber beispielsweise unter gleichbleibenden Bedingungen die Phosphatverfügbarkeit ab, hat erhöhtes $\mathrm{CO}_{2}$ keinen stimulierenden Einfluss mehr auf das Wachstum, wie Versuche an Leguminosen gezeigt haben. Die Verfügbarkeit anderer Ressourcen außer $\mathrm{CO}_{2}$ ist unter natürlichen Bedingungen aber meist begrenzt. Daher ist davon auszugehen, dass unter erhöhtem $\mathrm{CO}_{2}$ langfristig entweder die Photosynthesekapazität verringert wird oder eine Wachstumssteigerung bei Nährstoffverdünnung stattfindet, was

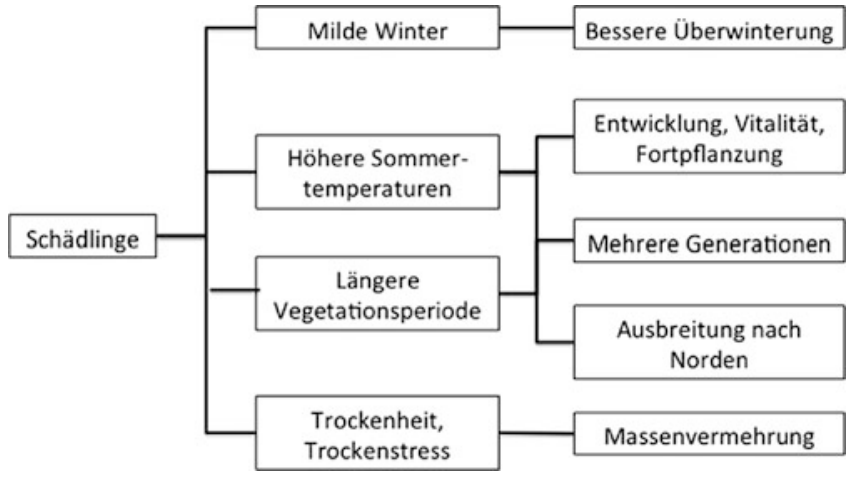

- Abb. 7.5 Mögliche Effekte des Klimawandels auf Schädlinge. (Chmielewski 2009)

sich z. B. durch größere C/N-Verhältnisse ausdrücken kann. Meist nimmt die Konzentration an nicht strukturgebundenen Kohlenhydraten wie Stärke und Zuckern bei sinkendem Proteingehalt zu. Demzufolge verändert sich die Nahrungsqualität für pflanzenfressende Organismen, sodass sich deren Wachstum und Reproduzierbarkeit verändern kann. Diese Wirkungskette zeigt, wie komplex erhöhtes $\mathrm{CO}_{2}$ auf die freie Natur wirken kann und dass Resultate aus Gewächshausversuchen kaum auf Ökosysteme übertragen werden können. In welchem Ausmaß zukünftig ein erhöhter atmosphärischer $\mathrm{CO}_{2}$-Gehalt das Pflanzenwachstum beeinflusst, hängt somit wesentlich vom Standort, von der Pflanzenart und den klimatischen sowie Bodenbedingungen ab.

\subsubsection{Veränderungen im Auftreten von Schadorganismen}

Die Klimaänderungen könnten auch Folgen für das Auftreten von Krankheiten, Pflanzenschädlingen und in der Landwirtschaft für Unkräuter haben und zu Ertragseinbußen oder gar zum Ausfall ganzer Kulturen oder Bestände führen. Müller (2009) und Petercord et al. (2009) unterscheiden zwischen direkten und indirekten Schadwirkungen als Folge veränderter Klimabedingungen. Direkte Wirkungen sind schadensinduzierende Reaktionen von Schadorganismen, indirekte Wirkungen betreffen Veränderungen der Prädisposition von Pflanzen und die daraus resultierenden Effekte von Schadfaktoren. Die Abschätzung der Wirkung von Schadorganismen unter geänderten Klimabedingungen ist nicht trivial, da zwischen Pathogenen (Viren, Bakterien, Pilze), Überträgern (Zwischenwirte) und Wirtspflanzen komplexe Wirkungsbeziehungen bestehen. Zudem haben potenzielle Schädlinge und Krankheiten natürliche Antagonisten, deren Wirkungseinfluss ebenfalls vom Klimawandel betroffen sein kann (Borner 2009).

Mildere Winter, höhere Sommertemperaturen, längere Vegetationsperioden und Trockenphasen können Effekte auf die Populationsdynamik von Schadorganismen haben (Chmielewski 2009) (- Abb. 7.5). Durch wärmere Sommer und verlängerte Vegetationsperioden nimmt die Lebensaktivität von Schadorganismen zu. In milderen Wintern sinkt die Mortalitätsrate von Schädlingen, was im Folgejahr zu höheren Befallsdichten führen kann. Bei einigen Insektenarten können sich höhere Sommertemperaturen negativ auswirken. Bei der Forleule (Panolis flammea), einem bedeutenden Kiefernschädling, führen höhere Temperaturen während der Schwärmzeit zu einer Verkürzung des Imaginalstadiums und zu 
einer unvollständigen Eiablage (Escherich 1931; Schwerdtfeger 1970). Trockene Sommer können sich auch mindernd auf Schäden durch Pilzkrankheiten auswirken, da Pilze in ihrer Entwicklung auf feuchte Bedingungen angewiesen sind.

Veränderte klimatische Bedingungen werden sich auch auf das Auftreten und die Häufigkeit von Ackerunkräutern auswirken. Durch höhere Temperaturen und geringere Niederschläge während der Sommermonate, eine erhöhte $\mathrm{CO}_{2}$-Konzentration, veränderte Licht- und Strahlungsverhältnisse und die Zunahme extremer Wetterereignisse können bestimmte Ackerunkräuter begünstigt werden. Geänderte Klimabedingungen fördern auch die Ansiedlung neuer, aus anderen Erdteilen stammender Pflanzen, sog. Neophyten. Verfügen diese über eine hohe Konkurrenzstärke und Reproduktionsrate sowie eine Herbizidunempfindlichkeit, können sie schnell Ackerflächen oder Grünland besiedeln und zu Ernteeinbußen führen. Ähnlich zu beurteilen sind sog. Upstarters, worunter opportunistische Unkrautarten verstanden werden, die bereits jetzt auf landwirtschaftlich genutzten Flächen vorkommen und von geänderten Klimabedingungen profitieren (Breitsameter et al. 2014).

\subsubsection{Minderungen}

Hinsichtlich des THG-Minderungspotenzials sind Land- und Forstwirtschaft unterschiedlich zu beurteilen. Durch die forstliche Produktion wird atmosphärisches $\mathrm{CO}_{2}$ gebunden. Eine Steigerung des Waldwachstums durch Bewirtschaftungsmaßnahmen erhöht die Bindungsleistung. Im Gegensatz hierzu werden durch die landwirtschaftliche Produktion THG-Emissionen freigesetzt, die im Wesentlichen durch eine Produktionsreduktion vermindert werden können.

Da die Verwendung von Stickstoffdünger eine bedeutende Quelle der THG-Emissionen der Landwirtschaft ist, zielen Minderungsstrategien auf die Verbesserung der N-Produktivität und einen sinkenden Stickstoffdüngereinsatz. Dies kann erreicht werden, indem u. a. die Ausbringungstechnik, die Düngemenge und der Düngezeitpunkt optimiert werden. Durch Steigerung der NProduktivität können bei jedem Kilogramm ausgebrachten Stickstoffdüngers bis zu $17,5 \mathrm{~kg} \mathrm{CO}_{2}$-Äquivalente eingespart werden (Flessa et al. 2012).

Ein weiteres Einsparpotenzial ergibt sich bei der Viehhaltung, die mit hohen Methanemissionen belastet ist. Durch die Steigerung der Milchleistung würden die mit dem Erhaltungsbedarf von Kühen einhergehenden THG-Emissionen auf eine höhere Produktmenge verteilt. Zusätzlich kann der Anteil des Milchkuhbestands, der jährlich durch Jungtiere ersetzt wird, erhöht werden. Dadurch sinkt zwar die Umtriebszeit von Milchkühen, gleichzeitig werden aber die THG-Emissionen von Jungfärsen reduziert (Osterburg et al. 2013).

Im Rahmen der EU-Richtlinie über erneuerbare Energien wird neben dem Anbau von Energiepflanzen die Umwandlung von Wirtschaftsdünger aus der Viehhaltung in Biogas empfohlen (EU 2009). Im Vergleich zur Biogasgewinnung aus Silomais bietet sich hier ein hohes Potenzial zur Vermeidung von THG-Emissionen, das sowohl aus dem Ersatz fossiler Energien als auch aus der Vermeidung von
THG-Emissionen bei der Lagerung von Wirtschaftsdünger resultiert. Nach Osterburg et al. (2013) könnten aus den rund 200 Mio. $t$ Wirtschaftsdünger, die jährlich in Deutschland anfallen, 3,46 Mrd. $\mathrm{m}^{3}$ Methan zur energetischen Nutzung erzeugt werden. Damit könnten $2 \%$ der deutschen Stromproduktion gedeckt werden.

Ökologische Landwirtschaft wird häufig als Möglichkeit zur Reduzierung des Energieverbrauchs und der THG-Emissionen beschrieben (Rahmann et al. 2008). Durch den Verzicht auf mineralischen Stickstoffdünger und Pestizide sowie den geringeren Viehbesatz werden die THG-Emissionen gegenüber der traditionellen Landwirtschaft verringert. Die Erzeugung der Futtermittel im Betrieb vermeidet Transportemissionen und Emissionen durch Landnutzungsänderungen in den Erzeugerländern von Futtermitteln (Osterburg et al. 2013).

Rahmann et al. (2008) beziffert die Kohlenstoffbindung durch ökologische Flächenbewirtschaftung mit durchschnittlich $400 \mathrm{~kg}$ $\mathrm{CO}_{2} \mathrm{ha}^{-1} \mathrm{a}^{-1}$. Nach Flessa et al. (2012) ist dies aber lediglich ein temporäres Phänomen, da bei Erreichen des Humusgleichgewichts im Boden keine weitere $\mathrm{CO}_{2}$-Bindung mehr erfolgt. Anhand einer Metaanalyse zeigten Skinner et al. (2014), dass die flächenbezogenen Stickoxidemissionen beim ökologischen Landbau signifikant niedriger sind als beim traditionellen Landbau. Werden die Stickoxidemissionen aber auf Produktmengen bezogen, schneidet der traditionelle Landbau signifikant besser ab. Kiefer et al. (2014) untersuchten 81 Landbaubetriebe und fanden bei der Milchproduktion in ökologischen Betrieben signifikant höhere $\mathrm{CO}_{2}$-Emissionen als bei traditionellen Betrieben.

Im Gegensatz zur Landwirtschaft führt Forstwirtschaft in der MRH zu positiven $\mathrm{CO}_{2}$-Effekten. $\mathrm{CO}_{2}$ wird in der ober- und unterirdischen Biomasse von lebenden und abgestorbenen Bäumen sowie im Boden und in der Streuauflage als Kohlenstoff (C) gebunden. Durch Abbau- und Zerfallsprozesse wird C wieder als $\mathrm{CO}_{2}$ in die Atmosphäre freigesetzt oder durch Holznutzung dem Waldspeicher entzogen.

Die Wälder der MRH weisen einen Holzvorrat von rund 203,6 Mio. $\mathrm{m}^{3}$ auf. Sie speichern rund 45,3 Mio. tC in der oberirdischen und weitere 8,5 Mio. tC in der unterirdischen Biomasse. Pro Hektar sind somit rund $95 \mathrm{tC}$ gebunden. Dieser Wert liegt etwa 10 Tonnen unter dem Durchschnittswert des gesamten Waldes in Deutschland. In den Wäldern der MRH wurden zwischen 2002 und 2012 jedes Jahr durchschnittlich 1,94 Mio. tC in der ober- und unterirdischen Biomasse gebunden. Dies entspricht den jährlichen $\mathrm{CO}_{2}$-Emissionen von knapp 3,4 Mio. $\mathrm{Pkw}^{2}$. In - Abb. 7.6 sind die durchschnittlichen jährlichen Werte für $\mathrm{Zu}$ wachs und Nutzung des oberirdischen C-Vorrats für den Zeitraum 2002-2012 abgebildet. Die größten Zuwächse zeigen Kiefer und Fichte, gefolgt von Eiche und Buche. Bei allen Baumarten ist der Zuwachs höher als die Nutzung. Auf jedem Hektar Wald werden pro Jahr durchschnittlich 2,9 tC in der oberirdischen Biomasse gebunden und 2,05 tC genutzt, sodass die C-Speicher der Wälder der MRH kontinuierlich zunehmen.

Minderungspotenziale in der Forstwirtschaft ergeben sich durch die $\mathrm{CO}_{2}$-Sequestrierung und C-Speicherung in Wäldern.

2 Annahme: $14.000 \mathrm{~km}$ Jahresfahrleistung (Quelle: Kraftfahrbundesamt) und $150 \mathrm{~g} \mathrm{CO}_{2} / \mathrm{km}$ pro Pkw. 


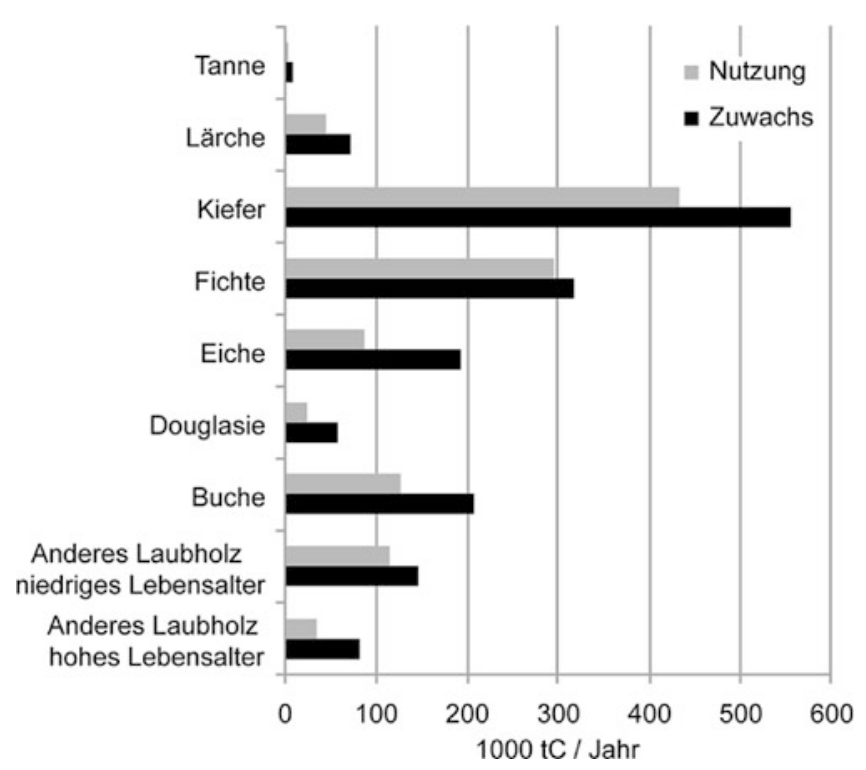

- Abb. 7.6 Durchschnittlicher jährlicher Zuwachs und Nutzung des oberirdischen C-Vorrats in den Wäldern der MRH [1000 tC/Jahr]. (Daten: Bundeswaldinventur, eigene Berechnungen)

Durch die Holznutzung kann ein bedeutender Teil des Kohlenstoffs aus dem Waldspeicher entfernt und in Holzprodukten wie Sägeholz oder Holzverbundwerkstoffen gespeichert werden. In der ersten Verpflichtungsperiode (VP) des Kyoto-Protokolls (KP) (2008-2012) wurden die Länder angehalten, Veränderungen des Kohlenstoffspeichers in Wäldern zu berichten. Holzprodukte waren von der Berichtspflicht ausgeschlossen. Daher wurde jede Holzentnahme aus Wäldern als unmittelbare Freisetzung von $\mathrm{CO}_{2}$ gewertet. Bei der UNFCCC-Vertragsstaatenkonferenz in Durban 2011 wurde entschieden, dass in der zweiten VP des KP (20132020) auch der Kohlenstoffspeicher in Holzprodukten angerechnet werden kann. Die unterschiedliche Behandlung von Holzprodukten in der ersten und zweiten VP des KP führte zu zwei Ansätzen, die heute die Diskussionen zu Wald und Klimaschutz bestimmen:

1. Der „Ökosystemansatz" betrachtet vor allem die klimapositiven Wirkungen des Waldes durch den Aufbau und Erhalt seines Kohlenstoffspeichers im Wald (• Abb. 7.7).

2. Der "Sektoransatz" berücksichtigt neben dem Kohlenstoffspeicher im Wald auch Emissionsminderungen und Speichereffekte durch Holzverwendung (• Abb. 7.8).

Unter dem Ökosystemansatz werden klimapositive Effekte durch Verzicht auf Holznutzung und daraus folgende Steigerung des stehenden Holzvorrats erreicht. Nutzungsverzicht wird zum Primat der Minderung des Klimawandels durch Wälder erhoben. Der Minderungseffekt durch Vorratssteigerung erfolgt in der Aufbauphase von Wäldern und geht in deren Klimaxphase in ein Gleichgewicht zwischen $\mathrm{CO}_{2}$-Bindung durch Biomasseaufbau und $\mathrm{CO}_{2}$-Freisetzung durch Biomasseabbau über (Otto 1994; Luyssaert et al. 2008). Bei der Betrachtung der Kohlenstoffbilanz von Wäldern spielt der Verbleib des Kohlenstoffs aus Zersetzungsprozessen eine entscheidende Rolle. Die zweite Bodenzustandserhebung (BZE 2) zeigt, dass in Deutschland die Kohlenstoffvorräte in Waldböden in etwa stabil geblieben oder sogar gestiegen

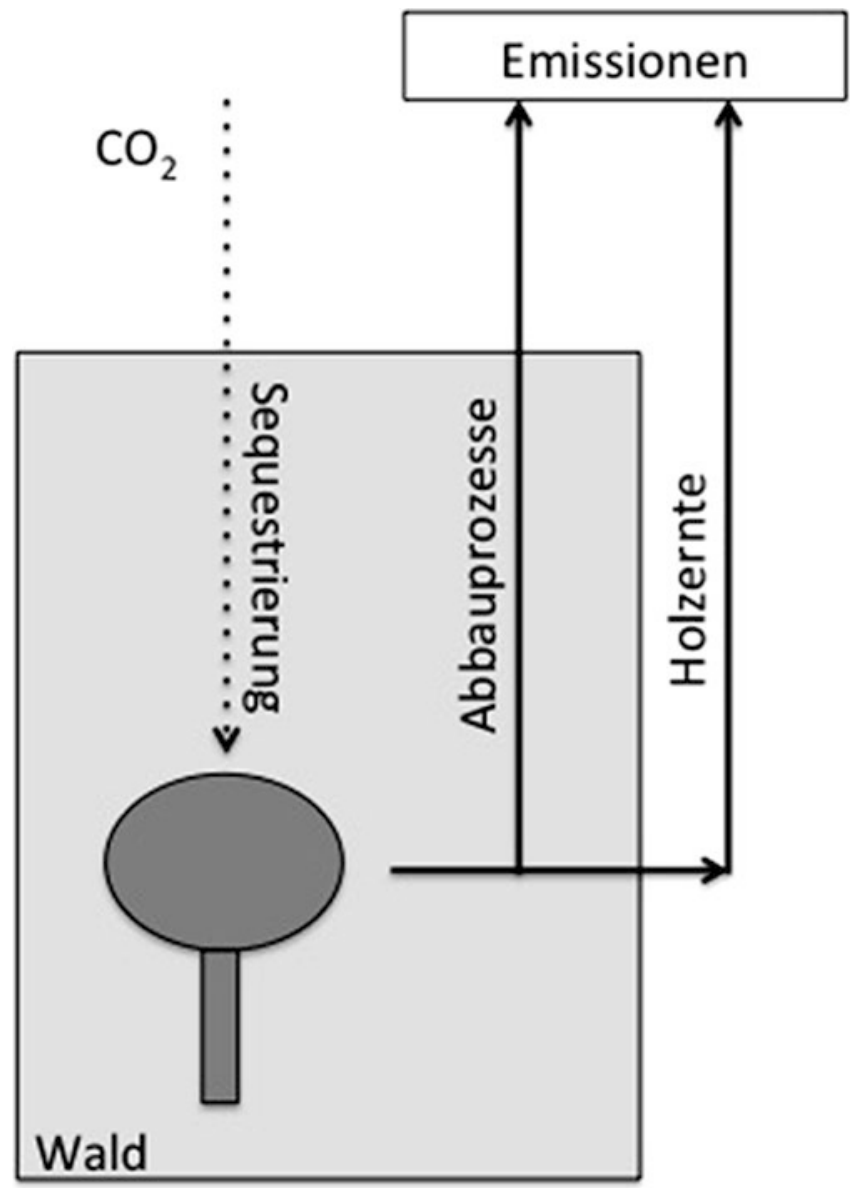

D Abb.7.7 C-Flüsse beim Ökosystemansatz

sind (Russ et al. 2011; Block und Gauer 2012; Umweltbundesamt 2014), obwohl die Wälder kontinuierlich genutzt werden.

Der Sektoransatz erlaubt eine Überführung von in Holz gebundenem Kohlenstoff vom Waldspeicher in den Produktspeicher und trägt der Tatsache Rechnung, dass die Holznutzung keine unmittelbare $\mathrm{CO}_{2}$-Freisetzung bewirkt. Neben der Speicherfunktion führen Holzprodukte durch die Substitution fossiler Energieträger zu einem Minderungseffekt:

- Durch energetische Nutzung von $\mathrm{Holz}$ werden $\mathrm{CO}_{2}$-Emissionen aus fossilen Energieträgern vermieden (energetische Substitution).

- Die Verwendung von Holz erfordert im Herstellungsprozess in der Regel weniger Energie als die Produktion alternativer funktionsgleicher Materialien und vermeidet Emissionen aus fossilen Energieträgern (stoffliche Substitution).

Etwa $80 \%$ der weltweit genutzten Holzmenge wird energetisch verwertet (Köhl et al. 2015). im Vergleich zu fossilen Energieträgern führt die energetische Verwertung von Holz aufgrund seines geringen Brennwertes $(15,5 \mathrm{TJ} / \mathrm{Gg})$ zu einer höheren $\mathrm{CO}_{2^{-}}$ Freisetzung. Bei nachhaltiger Waldbewirtschaftung übersteigt der C-Entzug aus dem Waldspeicher den C-Zufluss durch Holzzuwachs nicht, weshalb die durch energetische Verwertung freigesetzte Menge an $\mathrm{CO}_{2}$ zeitnah im Wald gebunden wird. Im Gegensatz zu fossilen Energieträgern wird daher kein zusätzliches 


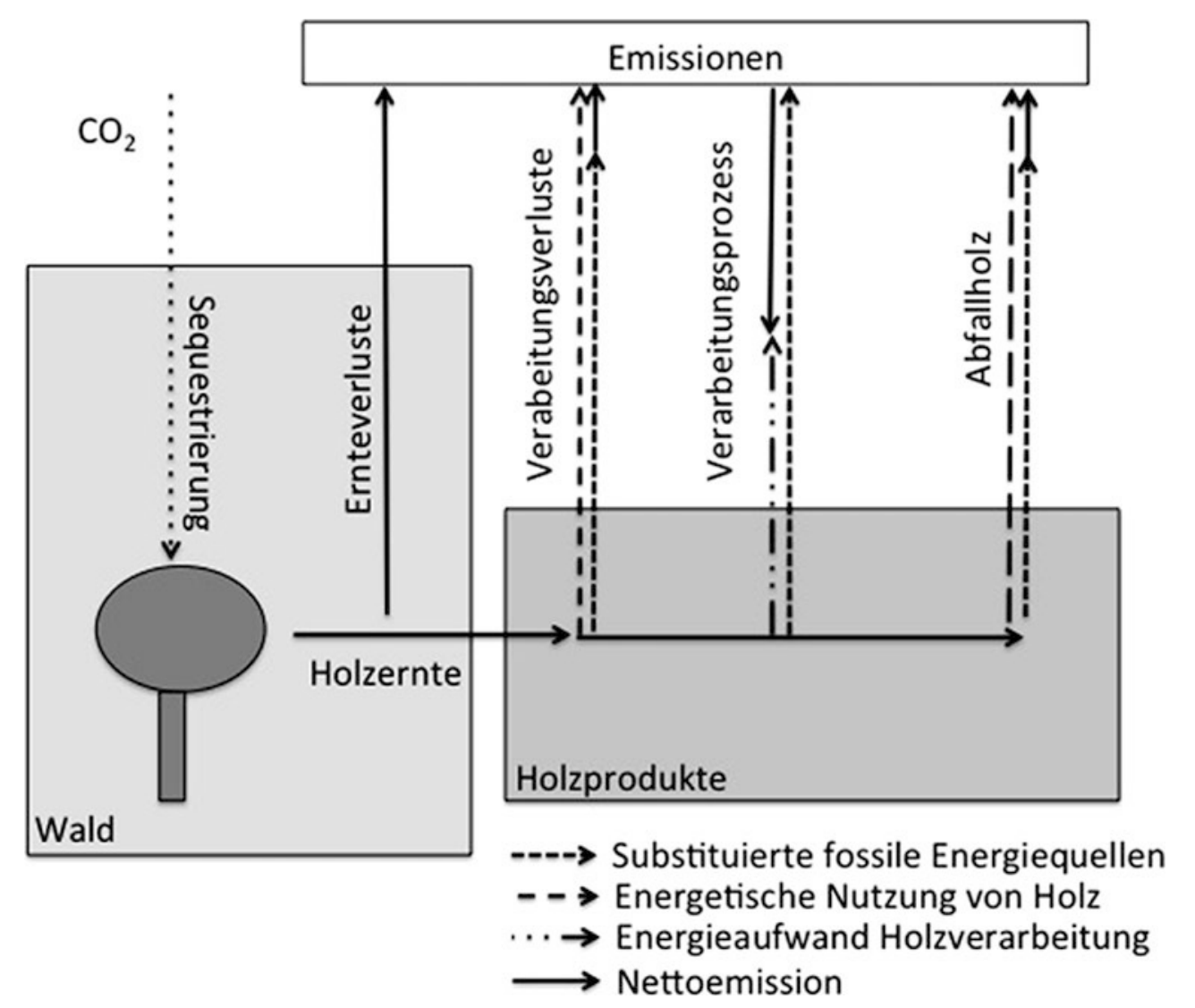

- Abb. 7.8 C-Flüsse beim Forstsektoransatz

$\mathrm{CO}_{2}$ in den globalen Kohlenstoffkreislauf eingebracht, sondern Kohlenstoff im System Atmosphäre-Wald-Holzprodukte verlagert. Daher stellt die energetische Substitution ein bedeutendes Minderungspotenzial dar (Knauf et al. 2015).

Holznutzung verringert die Kohlenstoffvorräte im Wald, führt aber bei stofflicher Verwertung nicht $\mathrm{zu} \mathrm{CO}_{2}$-Emissionen, sondern zu einer Verschiebung von Kohlenstoff vom Waldspeicher in den Produktspeicher (Pingoud et al. 2010; Sathre und O'Connor 2010). Die Herstellung von Holzprodukten erfordert weniger Gesamtenergie und damit THG-Emissionen als die Herstellung der meisten funktionsgleichen Materialien. Ersetzen Holzprodukte Materialien wie Zement, Stahl, Bausteine oder Aluminium, deren Herstellung mit hohen THG-Emissionen belastet ist, werden Emissionen aus fossilen Energieträgern vermieden. Die damit verbundenen Minderungseffekte können durch sog. Substitutionsfaktoren bewertet werden (Sathre und O'Connor 2010). Substitutionsfaktoren sind ein Index für die Effizienz, mit der die Verwendung von Holzbiomasse THG-Emissionen reduziert. Die Höhe der Substitutionsfaktoren hängt von der jeweiligen Anwendung und vom substituierten Material ab. Scharai-Rad und Welling (2002) verglichen den Energieaufwand von Einfamilienhäusern in Backstein- und Holzbauweise und fanden einen Substitutionsfaktor von 2,8 tC/ tC. Knight et al. (2005) ermittelten für den Vergleich von Türen aus Stahl- und Holzbauweise einen Substitutionsfaktor von 3,0 tC/tC. Sathre und O'Connor (2010) stellten in einer Metaanalyse die Dispositionsfaktoren aus verschiedenen Anwendungen im Baubereich zusammen und fanden einen mittleren Substitutionsfaktor von 2,1 tC/tC. Entscheidend für die Höhe der Substitutionsfaktoren ist auch die Verwendung der Holzprodukte am Ende ihrer Lebenszeit. Vorzugsweise erfolgt eine energetische Verwertung, die in Deutschland durch das Abfallbeseitigungsgesetz (BMJV 2002) geregelt ist.

Rüter et al. (2011) untersuchten die Speicher- und Substitutionswirkungen des deutschen Wald- und Holzsektors. Unter Zugrundelegung eines Basisszenarios, das die Waldbewirtschaftung um das Jahr 2002 zugrunde legt, ermittelten sie einen Beitrag des Sektors Wald und Holz zur Verringerung der $\mathrm{CO}_{2}$-Konzentration in der Atmosphäre von 105,5 Mio. t $\mathrm{CO}_{2 \mathrm{e}}$. $\mathrm{Zu}$ diesem Minderungspotenzial tragen vermiedene Emissionen durch Substitution einen Anteil von $82 \%$ bei.

Bei einer abschließenden Beurteilung des Minderungspotenzials der Forst- und Holzwirtschaft muss beachtet werden, dass sowohl Wald- als auch Produktspeicher nicht permanent sind, sondern nur vorübergehend wirken. Das gebundene $\mathrm{CO}_{2}$ kann innerhalb einer Zeitspanne von Tagen bis Jahrhunderten in die Atmosphäre freigesetzt und dann wieder durch Wälder sequestriert werden. Ersetzt Holz fossile Energieträger oder Materialien, deren Herstellung höhere THG-Emissionen verursacht, führt die Vermeidung von Emissionen aus fossilen Energiequellen durch die Verwendung von Holz zu einer permanenten $\mathrm{CO}_{2}$-Reduktion.

\subsubsection{Anpassung an den Klimawandel}

Gemäß IPCC wird Anpassung verstanden als die „Angleichung natürlicher oder anthropogener Systeme als Reaktion auf gegen- 
Tab. 7.6 Anpassungsmaßnahmen in der Landwirtschaft und Nutztierhaltung. (Nach Schaller und Weigel 2007)

\begin{tabular}{|c|c|}
\hline Maßnahme & Beispiele \\
\hline \multicolumn{2}{|l|}{ Landwirtschaft } \\
\hline \multirow{3}{*}{$\begin{array}{l}\text { Anpassung der Aussaat- } \\
\text { termine, Saatdichte, Reihen- } \\
\text { abstand und Fruchtfolge }\end{array}$} & Spät reifende Sorten mit hohem Ertragspotenzial \\
\hline & Anbau von zwei Hauptkulturen in einer Vegetationsperiode (bei ausreichender Wasserversorgung) \\
\hline & Verstärkter Anbau von Winterungen \\
\hline \multirow[t]{4}{*}{ Anbau anderer Sorten } & Vorverlegung des Aussaattermins und Anbau frühreifer Sorten \\
\hline & Hitze- und trockenresistente Sorten \\
\hline & Tief wurzelnde Kulturen \\
\hline & Wärmeliebende, schnellwüchsige, wassereffiziente Arten \\
\hline \multirow{3}{*}{$\begin{array}{l}\text { Anpassung der Boden- } \\
\text { bearbeitung }\end{array}$} & Verzicht auf wendende Bodenbearbeitung \\
\hline & Ausbringung einer Mulchschicht \\
\hline & $\begin{array}{l}\text { Tief lockernde Bodenbearbeitung mit anschließender Festigung des Oberbodens zur Verbesserung der Wasser- } \\
\text { speicherung }\end{array}$ \\
\hline \multirow{2}{*}{$\begin{array}{l}\text { Wasserversorgung/Be- } \\
\text { und Entwässerung }\end{array}$} & Tröpfchenbewässerung \\
\hline & Rückbau von Drainagesystemen \\
\hline \multirow{3}{*}{$\begin{array}{l}\text { Anpassung sonstiger Input- } \\
\text { größen }\end{array}$} & Ausreichende Nährstoffversorgung zur Ausnutzung des $\mathrm{CO}_{2}$-Düngeeffektes \\
\hline & „Precision farming" \\
\hline & Integrierter Pflanzenschutz \\
\hline Monitoring & Erstellung von Managementplänen \\
\hline \multicolumn{2}{|l|}{ Nutztierhaltung } \\
\hline \multirow{5}{*}{$\begin{array}{l}\text { Physikalische Veränderung } \\
\text { der Umgebung }\end{array}$} & Kühlungssysteme für intensive Tierzuchtbetriebe (Geflügel- und Schweinezucht) \\
\hline & $\begin{array}{l}\text { Belüftung, aktive Ventilation, Sprinkleranlagen zur Verminderung von Hitzestress in der Rinderzucht/Milchkuh- } \\
\text { haltung }\end{array}$ \\
\hline & Weidesysteme mit Baumbestockung zum Schutz der Tiere vor intensiver Bestrahlung \\
\hline & Stallhaltung und Fütterung bei verstärktem Winterniederschlag \\
\hline & Offene Wasserstellen zur Verbesserung der Thermoregulation der Tiere \\
\hline \multirow{3}{*}{$\begin{array}{l}\text { Genetische Entwicklung hitze- } \\
\text { toleranter Rassen }\end{array}$} & Hitzeresistenz \\
\hline & Verteilungsmuster der Schweißdrüsen \\
\hline & Hitze- und trockenstresstolerante Rassen \\
\hline \multirow[t]{4}{*}{$\begin{array}{l}\text { Verbesserung des Nährstoff- } \\
\text { managements }\end{array}$} & $\begin{array}{l}\text { Kompensation der verringerten Nahrungsaufnahme unter Hitzestress durch Erhöhung der Energiekonzentration } \\
\text { des Futters }\end{array}$ \\
\hline & Ausreichende Zufuhr von möglichst kaltem Wasser \\
\hline & Ausreichende Versorgung mit Mineralstoffen \\
\hline & Verlagerung der Fütterungszeiten \\
\hline
\end{tabular}

wärtige oder zukünftig zu erwartende klimatische Stimuli und ihrer Effekte, um Nachteile zu vermindern oder Vorteile zu nutzen".

Der zukünftige Klimawandel könnte die biologische Produktion der Land- und Forstwirtschaft in zweierlei Hinsicht betreffen:

- die zukünftige Erhöhung der Temperatur, die langfristige adaptive Maßnahmen erfordert, und

- die zunehmende Klimavariabilität wie Hitzewellen oder Dürreperioden, der durch kurzfristige Anpassungsmaßnahmen zu begegnen ist.
Laut OECD (2002) werden autonome, spontane von geplanten Anpassungsmaßnahmen unterschieden. Spontane Maßnahmen erfolgen überwiegend kurzfristig und reaktiv im privaten Sektor, während geplante Maßnahmen vorausschauend von der öffentlichen Hand initiiert werden und Vorgaben von Wissenschaft und Politik erfordern (Olesen und Bindi 2004).

Nach Schaller und Weigel (2007) können die in D Tab. 7.6 zusammengestellten Anpassungsmaßnahmen in der Landwirtschaft und der Nutztierhaltung erfolgen. Zusätzlich können Maßnahmen in der Pflanzenzüchtung auf die Anpassung der Ent- 
Tab. 7.7 Waldbewirtschaftung als Anpassungsmaßnahme. (Nach Lindner et al. 2008)

Natürliche Verjüngung

Selektion und Etablierung von besser angepassten, reproduktionsfähigen Baumarten oder Herkünften

Läuterungs- und Durchforstungsmaßnahmen

Holzernte

Waldumbau

Reduzierung des Risikos von abiotischen Schäden
Förderung der genetischen und Artendiversität

Sicherung einer ausreichenden Anzahl von Samenbäumen

Erhalt des Reproduktionspotenzials und der Fertilität

Anreicherungspflanzung zur Erhöhung der genetischen Variation

Einführung von Arten aus anderen Wuchsgebieten

Selektion von Pflanzmaterial mit hoher genetischer Diversität zum Erhalt oder zur Verbesserung der genetischen Anpassungsfähigkeit

Förderung von Herkünften, die besser an das zukünftige Klima angepasst sind

Läuterung (Stammzahlreduktion) in jungen Beständen zur Förderung von Mischbeständen

Höhere Durchforstungsintensitäten, bes. auf Trockenstandorten, zur Verringerung von Evapotranspiration und Trockenstress

Erhöhung der strukturellen Diversität

Ausbildung von stabilen Stämmen und damit Verringerung des Risikos von Sturmwurf

Einzelbaumnutzung statt Kahlschläge zum Erhalt von Dauerwaldgesellschaften

Vermeidung von Bodenschäden durch Maschineneinsatz

Umwandlung von Nadelholzreinbeständen in Mischbestände zur Reduzierung des Risikos von Insektenkalamitäten

Vermeidung des Waldbrandrisikos durch "fire-smart landscapes", Entfernung von Totholz, Änderung der Baumartenzusammensetzung

Reduzierung der Wilddichte zur Sicherung der Verjüngung von Laubhölzern

Verminderung des Sturmbruch- und Sturmwurfrisikos durch die Förderung standortangepasster Baumarten und Waldbaumaßbaumaßnahmen zur Förderung sturmresistenter Stammformen und Waldbestände wicklungsrate von Pflanzen an geänderte Klimabedingungen, die Verbesserung der Hitze- und Trockenheitstoleranz, die bessere Ausnutzung des $\mathrm{CO}_{2}$-Düngeeffektes oder die Erhöhung der Resistenz gegenüber Schädlingen und Krankheiten abzielen. Die erwarteten Veränderungen der Sommerniederschläge könnten besonders im südöstlichen Teil der MRH (Lüneburger Heide, Wendland), der von subkontinentalem Klima geprägt ist, verstärkte Bewässerungsmaßnahmen beim intensiven Ackerbau notwendig machen.

Anpassungsmaßnahmen in der Forstwirtschaft sind aufgrund der langen Lebenszeit von Bäumen meist langfristiger Natur. Der zeitliche Fortschritt des Klimawandels könnte die Fähigkeit von Waldökosystemen zur autonomen Anpassung an geänderte Umweltbedingungen überfordern. Aber auch die zunehmende Klimavariabilität kann die Forstwirtschaft vor Probleme stellen. Entscheidungen über geeignete Anpassungsmaßnahmen durch die Waldbewirtschaftung sind wegen der langfristigen Implikationen mit großen Unsicherheiten verbunden. Sie müssen einerseits kurzfristige Risiken wie Insektenkalamitäten, Waldbrände oder Sturmschäden eingrenzen, andererseits die langfristige Vitalität und Produktivität der Bestockung erhalten. Intensive Bewirtschaftungsmaßnahmen wie N-Dünung, Bewässerung oder der Einsatz von Pestiziden stellen im Wald aus ökonomischen und ökologischen Gründen keine sinnvollen Maßnahmen zur Vermeidung der Folgen von kurzfristig eintretenden Beeinträchtigungen dar.
Lindner et al. (2008) haben Anpassungsstrategien für europäische Wälder untersucht und mögliche Maßnahmen der Waldbewirtschaftung aufgezeigt (• Tab. 7.7).

\subsubsection{Zusammenfassung: Mögliche Auswirkungen des Klimawandels auf die Land- und Forstwirtschaft in der Metropolregion}

Land- und Forstwirtschaft sind von der globalen bis zur regionalen Ebene stark mit dem Klimawandel verknüpft und können zu einem bedeutenden Gegenstand des zukünftigen Klimawandels in der MRH werden, in der sie etwa $80 \%$ der Landfläche einnehmen.

Land- und Forstwirtschaft sind in einem komplexen Wirkungsgefüge mit dem Klimawandel verbunden. Sie gelten als bedeutende Ursache des Klimawandels, da sie durch Emissionen von Spurengasen und Freisetzung von $\mathrm{CO}_{2}$ infolge von Landnutzungsänderungen zur Erhöhung der Treibhausgaskonzentration der Atmosphäre beitragen. Der anthropogen verursachte Klimawandel könnte andererseits auch direkte Auswirkungen auf die Land- und Forstwirtschaft haben, da Temperaturanstieg, erhöhte $\mathrm{CO}_{2}$-Konzentrationen sowie veränderte Niederschlagsmuster und Extremwetterlagen die Wachstums- und Produktionsbedingungen beeinflussen. Da Pflanzen durch Photosynthese atmosphärisches $\mathrm{CO}_{2}$ binden, kann die biologische Produktion zu einer Senkung 
- Abb. 7.9 Prozentuale Verteilung der Seefischerei-Anlandungen der EU in der Nordsee im Jahr 2013. (Official Nominal Catches 2006-2013. Version XX-XX-2015. Marine Data Website)

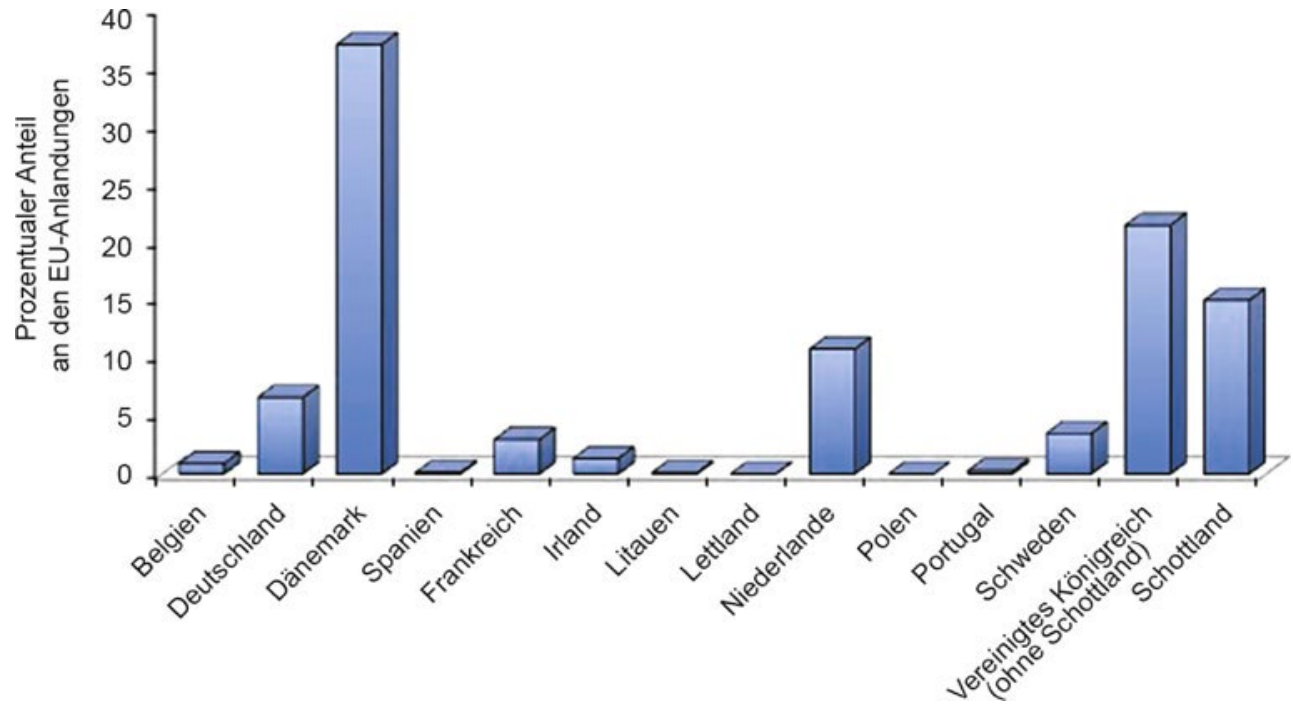

der $\mathrm{CO}_{2}$-Konzentration der Atmosphäre und dadurch zu einer Minderung des Klimawandels beitragen. Veränderte Umweltbedingungen erfordern eine entsprechende Anpassung der Landund Forstwirtschaft, die besonders für Wälder mit ihren langen Produktionszeiträumen weitreichende Maßnahmen erfordern.

In der MRH trägt die Landwirtschaft durch Emissionen - insbesondere Methan und Distickstoffoxid - aus der Tierhaltung und landwirtschaftlich genutzten Böden zur Erhöhung der THG-Konzentration der Atmosphäre bei. Die Wälder der MRH stellen keine Ursache des Klimawandels dar. Sie bilden eine Senke für atmosphärisches $\mathrm{CO}_{2}$, da der Holzzuwachs die Holznutzung übersteigt.

Der Faktorenkomplex aus Klima, Boden und Wasserverfügbarkeit bestimmt die landwirtschaftliche Produktion und das natürliche Vorkommen von Baumarten. Agronomische Auswirkungen des Klimawandels und dadurch bedingte Änderungen der Standortsfaktoren betreffen den Anbau von Kulturpflanzen und die Tierhaltung, Pflanzenschutzmaßnahmen durch veränderte Ausbreitungsmuster und Virulenz von Pathogenen und Krankheiten, zunehmenden Bewässerungsbedarf und Veränderungen der Bodenfruchtbarkeit. Mit zunehmender Wärme und länger anhaltenden Trockenperioden im Sommer können Bäume in Hitze- und Trockenstress geraten. Zudem werden das Wachstum und die Vitalität von Wäldern negativ beeinflusst. Die Folge wären Ertragseinbußen und eine geringere Kohlenstoffsequestrierung.

Mildere Winter sowie wärmere und trocknere Sommer könnten auch Folgen für das Auftreten von Krankheiten und Pflanzenschädlingen und in der Landwirtschaft für Unkräuter haben und zu Ertragseinbußen oder gar zum Ausfall ganzer Kulturen oder Bestände führen. In Waldbeständen würde besonders das Risiko für Borkenkäferkalamitäten und Waldbrände steigen.

Erhöhte $\mathrm{CO}_{2}$-Konzentrationen der Atmosphäre können das Pflanzenwachstum beeinflussen. Sie wirken auf das Wachstum von C3-Pflanzen, zu denen Bäume und die meisten landwirtschaftlichen Kulturpflanzen wie z. B. Getreide oder Hackfrüchte zählen, stimulierend, sofern kein Mangel an Licht-, Wasser- und Nährstoffversorgung besteht. Hingegen reagieren C4-Pflanzen wie Mais unter stark erhöhten $\mathrm{CO}_{2}$-Konzentrationen mit verringerter Biomasseproduktion.
Hinsichtlich des THG-Minderungspotenzials sind Land- und Forstwirtschaft unterschiedlich zu beurteilen. Durch die landwirtschaftliche Produktion werden THG-Emissionen freigesetzt, die durch Maßnahmen wie Produktionsreduktion, Düngemanagement oder Veränderungen der Viehhaltung vermindert werden können. Die Rolle der ökologischen Landwirtschaft wird unterschiedlich bewertet. Zwar sinken die Emissionen in Bezug zur bewirtschafteten Fläche, sie können aber steigen, wenn die Produktmengen als Vergleich herangezogen werden. Durch die forstliche Produktion wird atmosphärisches $\mathrm{CO}_{2}$ gebunden. Eine Steigerung des Waldwachstums durch Bewirtschaftungsmaßnahmen erhöht die Bindungsleistung.

Der zukünftige Klimawandel könnte unterschiedliche Anpassungsmaßnahmen in der Land- und Forstwirtschaft erforderlich machen. Eine mögliche zukünftige Erhöhung der Temperatur würde zur Notwendigkeit von langfristigen adaptiven Maßnahmen führen, während einer zunehmende Klimavariabilität wie Hitzewellen oder Dürreperioden mit kurzfristigen Anpassungsmaßnahmen zu begegnen wäre.

\subsection{Fischerei}

\subsubsection{Einleitung: Fischerei in der Nordsee und der Einfluss des Klimawandels}

Der größte wirtschaftliche Erlös der Fischerei in der MRH wird in der Nordsee erzielt. Diese Anlandungen aus der Nordsee entsprechen 27 \% der Eigenanlandungen Deutschlands und stellen somit den größten Anteil vor den Fängen aus dem Nordostatlantik und der Ostsee. Folglich konzentriert sich der folgende Abschnitt auf die Auswirkungen des Klimawandels auf die Fischerei der marinen lebenden Ressourcen der Nordsee. Die Nordsee ist eines der wichtigsten Fischereigebiete der Welt mit Fängen von um die 3,5 Mio. Tonnen an Fisch und Schalentieren, von denen die EU-Länder knapp 1,5 Mio. beitragen. Insgesamt stammt mit 55 \% auch ein Großteil der marinen Fänge der EU aus der Nordsee. Die kommerzielle Fischerei der Nordsee wird in der 


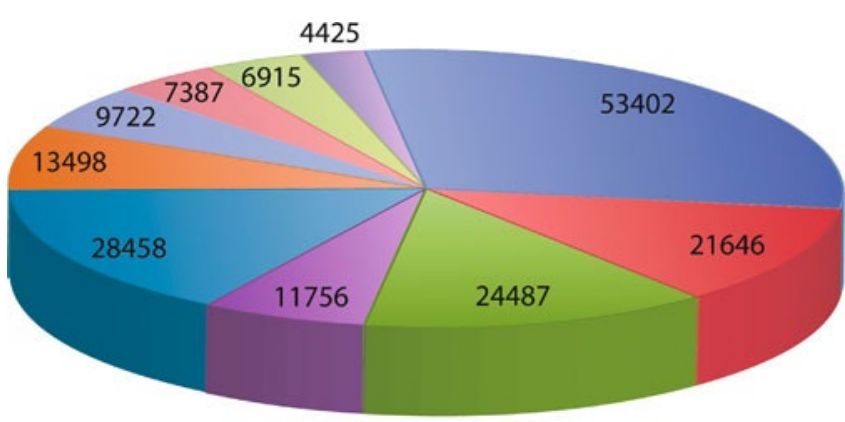

Hering

Holzmakrele

Blauer Wittling

Sprotte

Makrele

- Abb. 7.10 Anlandemengen in Tonnen der 10 wichtigsten Zielarten in der deutschen Fischerei im Jahr 2013. (BLE 2014)

Hauptsache von Norwegen, vom Vereinigten Königreich, von Dänemark, Russland, den Färöern, den Niederlanden sowie in geringerem Maße von Deutschland, Schweden, Frankreich und Belgien betrieben. Die Fänge der deutschen Flotte in der Nordsee umfassen rund 92.000 Tonnen, was etwa 6,5 \% der EU-Anlandungen (• Abb. 7.9) und knapp $3 \%$ der Gesamtanlandungen aus der Nordsee beträgt.

Die Nordseefischerei wird durch pelagische Arten wie Hering (Clupea harengus), Sprotte (Sprattus sprattus) und Makrele (Scomber scombrus) dominiert. Demersale Bodenfische und hier insbesondere Kabeljau (Gadus morhua), Schellfisch (Melanogrammus aeglefinus), Wittling (Merlangius merlangus) und Seelachs (Pollachius virens) sind ebenso von Bedeutung. Die deutsche Flotte untergliedert sich ganz grob in die überwiegend pelagische Hochseefischerei mit Hering, Makrele, Blauem Wittling und Holzmakrelen als wichtige Zielarten (s. 0 Abb. 7.9) und die kleine Kutter- und Küstenfischerei, die überwiegend in Nordund Ostsee aktiv ist. Für letzteres Segment sind in der Nordsee die Seelachsfischerei, die Grundschleppnetz- und Baumkurrenfischerei auf vermischte Grundfischbestände sowie die Krabbenfischerei von größerer Bedeutung (• Abb. 7.10).

Der Klimawandel manifestiert sich im Ökosystem Meer, und damit auch in der Nordsee, in vielfältiger Weise. Neben dem zu erwartenden Anstieg der mittleren Temperatur des Meerwassers gehört dazu auch eine Änderung in der Saisonalität, d. h. im jährlichen Auftreten der Frühjahrserwärmung und der herbstlichen Abkühlung. Weitere Einflüsse der zu erwartenden Klimaänderung sind:

1. Änderungen im Salzgehalt und in der Stratifizierung der Wassersäule (durch veränderte Niederschlags- und Flusswassereintragsmengen),

2. eine Änderung der chemischen Zusammensetzung des Meerwassers und hier insbesondere Änderungen in der Sauerstoffkonzentration und eine Versauerung sowie
3. ein häufigeres Auftreten und eine größere Intensität von Starkwindereignissen.

Diese Konsequenzen des Klimawandels haben nicht nur eine Bedeutung für die Biologie der von der Fischerei genutzten Arten, sondern auch vielfältige Konsequenzen für das Fischereimanagement.

Im Folgenden wird zuerst der Wissensstand zum Einfluss des Klimas auf die marinen lebenden Ressourcen der Nordsee zusammengefasst und ein Ausblick auf die weiteren zu erwartenden Änderungen gegeben. Im Anschluss werden mögliche Auswirkungen auf die Fischerei und das Fischereimanagement für die Nordsee beschrieben. Abschließend werden zukünftige Änderungen der Fischerei in der Nordsee und insbesondere für die deutsche Fischerei und damit die MRH diskutiert.

\subsubsection{Klimabedingte Änderungen in der Biologie der lebenden marinen Ressourcen}

Klimabedingte Änderungen im Meer haben vielfältige Auswirkungen auf die marinen lebenden Ressourcen. Im Weiteren werden Änderungen in der räumlichen Verteilung und den Jahrgangsstärken sowie der mögliche Effekt der Versauerung und neuer Krankheitserreger und Räuber diskutiert.

\subsubsection{1 Änderungen in der räumlichen Verteilung der Fischbestände und der Fischerei}

Änderungen in der Verteilung der kommerziell genutzten Fischbestände der Nordsee zeigen klare Zusammenhänge mit langfristigen Änderungen in der Wassertemperatur (Simpson et al. 2011). Analysen von fischereiunabhängigen Monitoringprogrammen in der Nordsee ergaben im Zeitraum von 1977 bis 2001 Änderungen der Verteilungszentren von 48 bis zu 403 km (Beare et al. 2004; Perry et al. 2005, Dulvy et al. 2008). Zudem wurde für die letzten 30 Jahre eine Erhöhung der mittleren Aufenthaltstiefe der demersalen Fischgemeinschaft von ca. 3,6 m pro Jahrzehnt beobachtet (Dulvy et al. 2008). Insgesamt zeigen deutlich mehr Arten (bis zu 8-fach) ein vergrößertes Verteilungsgebiet (Hiddink und ter Hofstede 2008). Die Erwärmung hat dabei in Nordwesteuropa generell zu einer Erhöhung der Bestandsgrößen von Warmwasserarten aus südlicheren Gebieten mit einer geringeren maximalen Körpergröße geführt. Dagegen hat die Abundanz von nördlichen großen Kaltwasserarten in der Nordsee deutlich abgenommen. Typisch für diese „subtropicalization“, die für die Nordsee, aber auch für die Ostsee beschrieben wurde, ist eine Änderung der Fischgemeinschaften von einer Dominanz durch Arten wie den Hering und die Sprotte hin zu einer Dominanz von Warmwasserarten wie Makrele, Holzmakrele (Trachurus trachurus), Sardine (Sardina pilchardus) und Sardelle (Engraulis encrasicolus) (Montero-Serra et al. 2015).

Neben den fischereiunabhängigen Monitoringprogrammen können auch kommerzielle Fangdaten Verteilungsänderungen der genutzten Fischbestände anzeigen. Analysen der Fangdaten von Arten wie Kabeljau, Schellfisch und Scholle (Pleuronectes platessa) ergaben klare Änderungen in der räumlichen Verteilung 
während der letzten 100 Jahre (Engelhard et al. 2011, 2014). Die höchsten Fänge des Kabeljaus werden dabei kontinuierlich weiter im Nordosten der Nordsee und damit auch in tieferen Gewässern erzielt. Für den Schellfisch zeigen die Fangdaten eine Verkleinerung des Aufenthaltsgebietes mit einer Änderung des südlichen Verbreitungsgebietes Richtung Norden, und die Scholle wird in zunehmendem Maße im Nordwesten der Nordsee gefangen (van Keeken et al. 2007). Entsprechende Studien bestätigen den Zusammenhang dieser Trends mit der Erwärmung des Wasserkörpers (Engelhard et al. 2014).

Die beobachteten klimabedingten Verteilungsänderungen der kommerziell genutzten Fischbestände und der damit einhergehenden Reorganisation der Fischgemeinschaft in der Nordsee bedeutet aber auch neue Nutzungsmöglichkeiten für die Fischerei. So wurde ein drastisch ansteigender Bestand des Europäischen Wolfsbarsches (Dicentrarchus labrax) in der südlichen Nordsee beobachtet und den ansteigenden Wassertemperaturen zugeschrieben (Pawson et al. 2007). Diese Art ist insbesondere auch für die Freizeit- und Angelfischerei von großer Bedeutung. Eine weitere für die Fischerei immer bedeutender werdende Art ist die Rote Meerbarbe (Mullus barbatus), welche die Nordsee zunehmend von Süden durch den Ärmelkanal, aber auch von Norden entlang der schottischen Küste bevölkert hat (Beare et al. 2005). Weitere neue Fangmöglichkeiten für die Fischerei bieten erhöhte Bestände des Europäischen Seehechtes (Merluccius merluccius) (Cormon et al. 2014) und des Kalmars der Art Loligo forbesi (Hastie et al. 2009).

Projektionen weiterer zukünftiger Veränderungen der Nordseefischgemeinschaft durch den Klimawandel wurden basierend auf einer Reihe von verschiedenen Modellierungstechniken erzielt. Diese Studien zeigen generell die Erwartung, dass global und im Nordostatlantik weitere Verteilungsänderungen auftreten werden (Cheung et al. 2009, 2010, 2011). Für die Nordsee sagen ähnliche Simulationen eine mittlere nördliche Verschiebung der genutzten Arten um 27 km voraus (Jones et al. 2012; Defra 2013). Dabei zeigte sich, dass Kalmare und Wolfsbarsch, aber auch Sardine und Sardelle zu den Arten mit den größten Veränderungen gehörten. Weitere Simulationsstudien zeigen das mögliche Verschwinden des Kabeljaus aus der Nordsee unter zukünftig erwarteten Temperaturbedingungen (Beaugrand et al. 2011) und eine weitere Nordverschiebung von anderen dorschartigen Fischen wie dem Schellfisch und dem Seelachs (Lenoir et al. 2011).

\subsubsection{2 Änderungen in den Jahrgangstärken genutzter Fischbestände}

Klimabedingte Änderungen in den Jahrgangsstärken sind neben der fischereilichen Nutzung die Hauptursache für Schwankungen in der Größe kommerziell genutzter Fischbestände. Die sog. Rekrutierung (Anzahl der überlebenden Nachkommen von der jährlichen Eiproduktion) ist ein Hauptmaß für die Produktivität der Fischbestände und oftmals abhängig von der Verfügbarkeit an Zooplankton für die frühen Larvenstadien (Cushing 1990), aber auch anderer Prozesse während der frühen Lebensstadien (Petitgas et al. 2012). Viele wissenschaftliche Studien zeigen den Zusammenhang zwischen der Rekrutierung und der Größe der kommerziellen Fänge unter den klimatischen Bedingungen für Arten wie z. B. Kabeljau (Brander und Mohn 2004; Cook und
Heath 2005; O’Brien et al. 2000), Scholle (Brunel und Boucher 2007), Hering (Nash und Dickey-Collas 2005), Makrele (Jansen und Gislason 2011) und Wolfsbarsch (Pawson 1992). Diese Studien nutzen zumeist die Oberflächentemperatur oder Indizes für klimatische Änderungen durch z. B. die Nordatlantische Oszillation (NAO) oder die Atlantische Multidekadische Oszillation (AMO) als Vorhersagevariablen für den Rekrutierungserfolg und damit für die Größe des Nachwuchsjahrgangs. Für Letztere wurde ein Zusammenhang mit den Beständen des Herings, der Sardelle und der Sardine für die Nordsee gezeigt (Alheit et al. 2012; Gröger et al. 2010). Ein Großteil solcher Studien für die Nordsee beschäftigte sich mit dem Kabeljau und zeigte, obwohl regional unterschiedlich (Planque und Frédou 1999), den negativen Einfluss der Erwärmung für diese kommerziell wichtige Art (O'Brien et al. 2000; Beaugrand et al. 2003; Drinkwater 2005; Heath und Brander 2001).

Ein möglicher Prozess, der zu Schwankungen in der Jahrgangsstärke der Fischbestände führen kann, ist ein sog. Mismatch mit der Planktonproduktion (Cushing 1990). Grund hierfür können sowohl Änderungen im Auftreten (zeitlich, aber auch räumlich) der Fischlarven oder ihrer Nahrung, dem Zooplankton, durch klimatische Schwankungen sein. Änderungen im saisonalen Auftreten des Planktons, insbesondere des Copepoden Calanus finmarchicus, haben so wahrscheinlich zur Reduzierung der Rekrutierung des Kabeljaus, aber auch vieler Plattfischbestände beigetragen (Beaugrand et al. 2003; Reid et al. 2001, 2003).

Über eine kontinuierliche Reduzierung der Nachwuchsproduktion kann der Klimawandel zu einer vergrößerten Anfälligkeit der Fischbestände gegenüber der Fischerei führen. Für die Nordseearten Kabeljau, Schellfisch, Wittling, Seelachs, Scholle und Seezunge (Solea solea) ergab eine Untersuchung des Zusammenhangs zwischen Wassertemperatur und Rekrutierung, dass für viele Bestände bei der weiteren Erwärmung kleinere Fischereien zu erwarten sind (Cook und Heath 2005). Ähnliche Studien bestätigen dies z. B. für die Makrele in der Nordsee (Jansen und Gislason 2011; Jansen et al. 2012; Mendiola et al. 2007).

\subsubsection{Der Einfluss der Versauerung auf die lebenden Ressourcen}

Eine weitere Folge des Klimawandels (neben der Erwärmung) ist die Versauerung des Meerwassers (Pörtner et al. 2014). Auch für die Nordsee zeigen Modellprojektionen eine Versauerung durch die vermehrte Aufnahme von Kohlendioxid aus der Luft durch das Meerwasser (Artioli et al. 2012). Die Versauerung hat möglicherweise direkte und indirekte Einflüsse auf die Rekrutierung, das Wachstum und das Überleben der genutzten Fischbestände (Fabry et al. 2008; Llopiz et al. 2014), die durch die Erwärmung noch verstärkt werden können (Hale et al. 2011). Dabei sind zuerst Tiere mit Hüllen und Skeletten aus Kalziumkarbonat wie Mollusken, Crustaceen und Echiondermen gefährdet (Kroeker et al. 2010; Hendriks et al. 2010), und Effekte sind dokumentiert für Miesmuschel, Austern, Hummer und Kaisergranat (Nephrobs norvegicus) (Agnalt et al. 2013; Gazeau et al. 2010; Styf et al. 2013).

Direkte Effekte auf kommerzielle Fischbestände sind bisher wenig dokumentiert, und Experimente mit den Nordseearten Hering und Kabeljau haben gezeigt, dass diese relativ robust gegenüber der Versauerung sind (Franke und Clemmesen 2011). 
Andere Studien zeigen, dass indirekte Effekte über das Nahrungsnetz möglicherweise von größerer Bedeutung sind (Le Quesne und Pinnegar 2012). Es ist aber klar, dass hier noch ein erheblicher Forschungsbedarf besteht.

\subsubsection{Neue Krankheitserreger und Räuber}

Ein bedeutendes Problem für die Nordseefischerei ist der $\mathrm{Zu}$ sammenhang zwischen dem Klimawandel und dem Auftreten von Krankheitserregern. Global steigt das Auftreten mariner Pathogene mit der Erwärmung an (Harvell et al. 1999). In europäischen Schalentieren kommen insbesondere die Bakterien Vibrio (V.) parahaemolyticus und V. vulnificus vor, die sehr von den vorherrschenden Salzgehalts- und Temperaturbedingungen abhängig und gefährlich für die menschliche Gesundheit sind (Baker-Austin et al. 2013). Diese Vibrio-Arten vermehren sich insbesondere bei Temperaturen $>18^{\circ} \mathrm{C}$, und starke Ausbrüche treten in Europa vermehrt während sommerlicher Hitzewellen auf. Andere Pathogene wie das Norovirus treten häufig während kalter Winter nach Perioden mit starken Niederschlägen und dem darauffolgenden Abfluss von Wasser aus Kanalisationen auf (Campos und Lees 2014). Insgesamt kann das Auftreten dieser Pathogene zur zeitlich begrenzten Schließung von Fischereien führen.

Der Klimawandel wird außerdem zum Auftreten neuer Räuberarten und damit zu Veränderungen in den Nahrungsnetzen, welche die genutzten Arten produzieren, führen. Ein gut dokumentiertes Beispiel ist hier der Graue Knurrhahn (Eutriglia gurnardus), der sich in die nördliche Nordsee ausgebreitet hat (Kempf et al. 2014). Der Graue Knurrhahn ist eine Bedrohung für den Nachwuchs des Kabeljaus geworden, mit Folgen für die Rekrutierung dieser schon durch die Erwärmung bedrohten Art. Ähnliche Folgen mag die Ausbreitung des Europäischen Seehechtes in die nördliche Nordsee haben, die zusätzlich auch ein Nahrungskonkurrent für den Seelachs ist (Cormon et al. 2014). Unklarheit besteht auch über die Bedeutung des Klimawandels für das vermehrte Auftreten von gelatinösem Plankton (d. h. Quallen) (Lynam et al. 2004; Atrill et al. 2007), die negative Auswirkungen als Konkurrenten und Räuber für die Larvenstadien der kommerziell genutzten Fischarten haben können.

\subsubsection{Konsequenzen der biologischen Änderungen für die Fischerei}

Klimabedingte Änderungen in der Verteilung und Rekrutierung und somit der lokalen Bestandsgrößen haben möglicherweise starke Auswirkungen auf die Verfügbarkeit der lebenden Ressourcen für die kommerzielle Fischerei. Insbesondere räumliche Veränderungen führen zu Problemen im Fischereimanagement, wo die Verteilung von Arten sich über „politische Grenzen“ ändert. So hat die Abwanderung der Makrele aus norwegischen Gewässern in die Nordsee zu Konflikten zwischen norwegischen Fischereischiffen und der britischen Fischereikontrolle geführt. Gleichzeitig haben Island und die Färöer-Inseln eine Makrelenquote für sich gefordert, da der Bestand in ihre territorialen Gewässer eingewandert ist. Ein ähnliches Problem besteht im Ärmelkanal und in der südlichen Nordsee durch die Ausbreitung der Sardelle. Da die Sardellen- bestände der französischen und spanischen Fischerei erschöpft sind, besteht Uneinigkeit, inwieweit diese Zugang zu den nun nördlicheren Verbreitungsgebieten der Scholle bekommen sollen. Mit dem Klimawandel werden solche Konflikte möglicherweise vermehrt auftreten (Link et al. 2011).

Darüber hinaus haben grundlegende und langfristige Änderungen im Artengefüge der Nordsee Auswirkungen auf die Verteilungsschlüssel der Fangquoten zwischen den EU-Nationen. Im heutigen Managementsystem der Europäischen Union gibt es eine fein austarierte Balance zwischen den Fanganteilen der einzelnen Fischereinationen, die auf der historischen Verteilung der Fangrechte beruht. Diese historischen Fangrechte spiegeln weitgehend auch die Zusammensetzung der Fänge in den für die jeweiligen Nationen typischen Fischereien wider. In der Nordsee, die durch diverse Fischgemeinschaften gekennzeichnet ist, sind dies häufig sog. gemischte Fischereien, die eine Vielzahl von Arten gleichzeitig fangen. Folglich wird jede Managemententscheidung für eine Art indirekte Auswirkungen auf die mitgefangenen Arten haben. Ändert sich die Fangbarkeit der Zielarten durch Verschiebungen in der räumlichen Verteilung oder Produktivität der Bestände, muss dieses „relative Stabilität“ genannte Prinzip der Quotenverteilung politisch neu verhandelt werden. Die schon heute mit der 2013erReform der Gemeinsamen Fischereipolitik der EU beobachteten politischen Widerstände gegen ein Aufweichen der relativen Stabilität durch handelbare Fangquoten (Kraus und Döring 2013) lassen befürchten, dass hier neue politische Gräben entstehen werden. Verschärft wird die Situation durch das sog. Anlandegebot, das den Rückwurf von gefangenen Fischen weitgehend verbietet. Wenn die Quote für eine Art ausgeschöpft ist, dürfen die überzähligen Fische nicht mehr zurückgeworfen werden. Folglich muss eine gemischte Fischerei sofort gestoppt werden, wenn die Art mit der geringsten Quote ausgefischt ist. Die relative Stabilität verhindert, dass Flexibilität in der Quotenverteilung zwischen den Mitgliedstaaten das Problem löst. Im Falle der klimabedingten Ausbreitung des Seehechtes, für den die Nordseeanrainer traditionell nur sehr geringe Quotenanteile halten, führt dies möglicherweise zu einer zu frühzeitigen Schließung der Fischerei mit starken finanziellen Auswirkungen auf die Fischer (Baudron und Fernandez 2015). Ähnliche Fälle werden mit einem verstärkten Klimawandel vermehrt erwartet.

Klimabedingte Verteilungsänderungen der kommerziellen Fischbestände haben auch einen Einfluss auf die Effektivität von Schutzgebieten (van Keeken et al. 2007), deren Einrichtung eine Maßnahme der Gemeinsamen EU-Fischereipolitik zum Schutz von Aufzucht- und Laichgebieten ist. In der Nordsee bestehen Schutzgebiete für Scholle, Hering, Stintdorsch (Trisopterus esmarkii) und Sandaal (Ammodytes tobianus). Für die Scholle besteht seit 1989 eine sog. Schollenbox zum Schutz vor Beifang und Discard von juvenilen Tieren, in der lediglich Fangfahrzeuge der kleinen Küstenfischerei fangen dürfen und große, hoch effizient fangende Fahrzeuge mit mehr als 300 PS ausgeschlossen sind. Der Klimawandel hat aber offensichtlich dazu geführt, dass sich die einjährigen Schollen zunehmend aus dem Gebiet der Box in tiefere, küstenfernere Gebiete begeben, was diese zu einem weniger effektiven Mittel des Fischereimanagements macht. Ähnliche Effekte werden bei der zu erwartenden Erwärmung in der Zukunft für die anderen Bestände auftreten (Cheung et al. 2012). 


\subsubsection{Zusammenfassung: Mögliche Auswirkungen des Klimawandels für die deutsche Fischerei in der Nordsee}

Im 5. Sachstandsbericht des IPCC (Pörtner et al. 2014) wird prognostiziert, dass in den nächsten 50 Jahren die globale Produktivität der Ozeane mit steigenden Temperaturen abnehmen wird und damit auch die möglichen Erträge der Fischereiwirtschaft - und das im mehrstelligen Milliarden-Dollar-Bereich. Es wird allerdings regional große Unterschiede geben. Die gemäßigten und höheren Breiten und somit auch die Nordsee und ihre Fischbestände werden von den geänderten Umständen eher profitieren, während es in den niedrigeren Breiten viele negative Auswirkungen geben wird, die einige der weltweit größten Fischereien massiv betreffen werden. Belastbare quantitative Vorhersagen der Auswirkungen des Klimawandels auf die Entwicklung der Nordseefischbestände und ihre Fischereien lassen sich heute noch nicht treffen. Die Unsicherheiten der regionalen Klimamodelle sowie die Komplexität der biologischen Interaktionen sind zu groß. Grundlegende Trends zeichnen sich allerdings schon heute ab:

- Global wird die verminderte Sauerstoffaufnahmekapazität wärmeren Wassers als einer der wichtigsten Faktoren für die prognostizierte Abnahme der Produktivität benannt. Auch das Wasser in der Nordsee wird in der Zukunft deutlich wärmer sein und deswegen weniger Sauerstoff aufnehmen können. Durch die großen Temperaturunterschiede zwischen Sommer und Winter in der Nordsee bricht in aller Regel die Schichtung der oberen Wasserschichten regelmäßig auf, und das Wasser durchmischt sich vollständig. Deswegen sind keine gravierenden physiologischen Auswirkungen oder ein Rückgang der Produktion durch Sauerstoffmangel zu erwarten. Wachstumsraten der Fische werden bei ausreichender Nahrungsverfügbarkeit steigen. Das heißt, bezogen auf das Sauerstoffproblem werden die Fischbestände der Nordsee eher zu den Profiteuren der wärmeren Wassertemperaturen gehören, wobei diese Betrachtung die prognostizierte Zunahme von Extremereignissen nicht einschließt.

- Die Erwärmung der Nordsee hat schon heute zu einer Zunahme an fischereilich interessanten, $z$. T. hochpreisigen Arten wie Wolfsbarsch und Roter Meerbarbe oder auch Sardellen geführt. Verschiedene Cephalopodenarten dehnen sich ebenfalls massiv in die Nordsee aus und dominieren z. B. im Nordosten Schottlands schon über traditionelle Zielarten der Fischerei (Hastie et al. 2009). Einige für die deutsche Fischerei traditionell wichtige Nordseearten wie die Nordseegarnele, Scholle oder auch Makrele haben sich mit steigenden Wassertemperaturen ebenfalls deutlich positiv entwickelt. So ist zu erwarten, dass trotz eines langfristigen Rückgangs kaltadaptierter Arten wie z. B. dem Kabeljau die deutsche Fischerei in der Nordsee von den neuen Arten und der positiven Entwicklung der anpassungsfähigen heutigen Zielarten profitieren kann. Fischerei und Management werden sich jedoch an die neuen Gegebenheiten anpassen müssen, um in der sich stark ändernden Umgebung konkurrenzfähig zu bleiben.
Neben den technischen Anpassungen besteht eine große Herausforderung darin, auf der Managementseite eine gerechte Verteilung der neuen Fangoptionen zu erreichen.

- Weil der Klimawandel sich auf die Verteilung und Produktivität der Bestände in der Nordsee auch über die Grenzen der nationalen Hoheitsgewässer der EU-Staaten hinaus auswirken wird und damit auf die politische Dimension der Fangmöglichkeiten, wird die Ökonomie der Fischereiwirtschaft in Europa und Deutschland ebenfalls betroffen sein. Bioökonomische Modellstudien prognostizieren allerdings, dass die Größe der ökonomischen Konsequenzen eher davon abhängt, wie sich die Gesellschaft und die Märkte auf die Situation einstellen, als von den Klimawandelauswirkungen selbst (Merino et al. 2010). Arnason (2007) zeigte z. B., dass die für Island positiven fischreichen Auswirkungen des Klimawandels im Hintergrundrauschen der Schwankungen des Bruttoinlandsproduktes mehr oder weniger aufgesogen werden. So werden die möglichen positiven ökonomischen Effekte bei gut funktionierender Anpassung der deutschen Nordseefischerei an den Klimawandel vielleicht regional noch sichtbar bleiben, aber gesamtwirtschaftlich ohnehin aufgrund der geringen Bedeutung des Sektors keine Relevanz entfalten.

\section{Literatur}

Agnalt AL, Grefsrud ES, Farestveit E, Larsen M, Keulder F (2013) Deformities in larvae and juvenile European lobster (Homarus gammarus) exposed to lower $\mathrm{pH}$ at two different temperatures. Biogeosciences 10:7883-7895

Alheit J, Pohlmann T, Casini M, Greve W, Hinrichs H, Mathis M, O'Driscoll K, Vorberg R, Wagner C (2012) Climate variability drives anchovies and sardines into the North and Baltic Seas. Prog Oceanogr 96:128-139

Arnason R (2007) Climate change and fisheries, assessing the economic impact in Iceland and Greenland. Nat Resour Model 20:163-197

Artioli Y, Blackford JC, Butenschön M, Holt JT, Wakelin SL, Thomas TH, Borges AV, Allen JI (2012) The carbonate system in the North Sea: Sensitivity and model validation. J Marine Syst 102-104:1-13

Atrill MJ, Wright J, Edwards M (2007) Climate-related increases in jellyfish frequency suggest a more gelatinous future for the North Sea. Limnol Oceanogr 52:480-485

Baker-Austin C, Trinanes JA, Taylor NGH, Hartnell R, Siitonen A, Martinez-Urtaza J (2013) Emerging Vibrio risk at high latitudes in response to ocean warming. Nat Clim Chang 3:73-77

Bakkenes M, Alkemade JRM, Ihle F, Leemans R, Latour JB (2002) Assessing effects of forecasted climate change on the diversity and distribution for European higher plants for 2050. Glob Change Biol 8:390-407

Baudron AR, Fernandez PG (2015) Adverse consequences of stock recovery: European hake, a new "choke" species under a discard ban? Fish Fish 16(4):563-575

Beare D, Burns F, Peach K, Portilla E, Greig T, McKenzie E, Reid D (2004) An increase in the abundance of anchovies and sardines in the north-western North Sea since 1995. Glob Change Biol 10:1209-1213

Beare D, Burns F, Jones E, Peach K, Reid D (2005) Red mullet migration into the northern North Sea during late winter. J Sea Res 53:205-212

Beaugrand G, Brander KM, Lindley JA, Souissi S, Reid PC (2003) Plankton effect on cod recruitment in the North Sea. Nature 426:661-664

Beaugrand G, Lenoir S, Ibañez F, Manté C (2011) A new model to assess the probability of occurrence of a species, based on presence-only data. Mar Ecol Prog Ser 424:175-190

Bissolli P, Müller-Westermeier G, Dittmann E, Remisová V, Braslavská O, Stastný P (2005) 50-year time series of phenological phases in Germany and Slovakia: a statistical comparison. Meteorol Z 14:173-182 
BLE (2014) Die Hochsee- und Küstenfischerei in der Bundesrepublik Deutschland im Jahre 2014. Bericht über die Anlandungen von Fischereierzeugnissen durch deutsche und ausländische Fischereifahrzeuge. Bundesanstalt für Landwirtschaft und Ernährung (BLE), Hamburg

BLE (2015) Waldbrandstatistik der Bundesrepublik Deutschland 2011, 2012, 2013, 2014. Bundesanstalt f. Landwirtschaft u. Ernährung, Bonn

Block J, Gauer J (2012) Waldbodenzustand in Rheinland-Pfalz. In: Mitteilungen aus der Forschungsanstalt für Waldökologie und Forstwirtschaft Rheinland-Pfalz 70/12. Forschungsanstalt für Waldökologie und Forstwirtschaft Rheinland-Pfalz, Trippstadt, S 228

BMJV (2002) Verordnung über Anforderungen an die Verwertung und Beseitigung von Altholz (Altholzverordnung - AltholzV)

Bohn U, Neuhäusl R (2003) Karte der natürlichen Vegetation Europas. BfN Schriftenreihe. BfN, Bonn

Bolte A, lbisch P, Menzel A, Rothe A (2008) Was Klimahüllen uns verschweigen. AFZ Wald 15:800-803

Borner H (2009) Pflanzenkrankheiten und Pflanzenschutz. Springer, Dordrecht

Brander KM, Mohn R (2004) Effect of the North Atlantic Oscillation on the recruitment of Atlantic cod (Gadus morhua). Can J Fish Aquat Sci 61:15581564

Breitsameter L, Bürger J, Edler B, Peters K, Gerowitt B, Steinmann H-H (2014) Klimafolgenforschung zu Ackerunkräutern - Daten, Methoden und Anwendungen auf verschiedenen Skalen. In: 26th German Conference on weed Biology and Weed Control Braunschweig. Julius-Kühn-Archiv 443.

Brunel T, Boucher J (2007) Long-term trends in fish recruitment in the north-east Atlantic related to climate change. Fish Oceanogr 16:336-349

Bürgerschaft der Freien und Hansestadt Hamburg (2014) Agrarpolitisches Konzept 2020. In: Mitteilungen des Senats an die Bürgerschaft Hamburg, S 32

Campos CJA, Lees DN (2014) Environmental transmission of human noroviruses in shellfish waters. Appl Environ Microbiol 80:3552-3561

Cheung WWL, Lam VWY, Sarmiento JL, Kearney K, Watson R, Pauly D (2009) Projecting global marine biodiversity impacts under climate change scenarios. Fish Fish 10:235-251

Cheung WWL, Lam VWY, Sarmiento JL, Kearney K, Watson R, Zeller D, Pauly D (2010) Large-scale redistribution of maximum fisheries catch potential in the global ocean under climate change. Glob Change Biol 16:24-35

Cheung WWL, Dunne J, Sarmiento JL, Pauly D (2011) Integrating ecophysiology and plankton dynamics into projected maximum fisheries catch potentia under climate change in the Northeast Atlantic. ICES J Mar Sci 68:10081018

Cheung WWL, Pinnegar JK, Merino G, Jones MC, Barange M (2012) Review of climate change and marine fisheries in the UK and Ireland. Aquat Conserv 22:368-388

Chmielewski F-M (2009) Landwirtschaft und Klimawandel. Geogr Rdsch 61(9):28-35

Chmielewski F-M (2011a) Wasserbedarf in der Landwirtschaft. In: Lozán JL, GraßI H, Hupfer P, Karbe L, Schönwiese C-D (Hrsg) Warnsignal Klima: Genug Wasser für alle? Universität Hamburg, Institut f. Hydrobiologie, Hamburg

Chmielewski F-M (2011b) Der Einfluss des Klimawandels auf den Wirtschaftssektor Landwirtschaft. In: von Storch H, Claussen M (Hrsg) Klimabericht für die Metropolregion Hamburg. Springer, Heidelberg, S 211-227

Chmielewski F-M, Köhn W (1999) Impact of weather on yield components of spring cereals over 30 years. Agr For Meteorol 96:4-58

Chmielewski F-M, Köhn W (2000) Impact of weather on yield components of winter rye over 30 years. Agric For Meteorol 102:253-261

Chmielewski F-M, Rötzer T (2001) Response of tree phenology to climate change across Europe. Agr For Meteorol 108:101-112

Chmielewski FM, Müller A, Bruns E (2004) Climate changes and trends in phenology of fruit trees and field crops in Germany, 1961-2000. Agr For Meteorol 121:69-78

Chmielewski F-M, Blümel K, Pálesová I (2012) Climate change and possible shifts of dormancy release for deciduous fruit crops in Germany. Clim Res 54:209-219

Cook RM, Heath MR (2005) The implications of warming climate for the management of North Sea demersal fisheries. ICES J Mar Sci 62:1322-1326

Cormon X, Loots C, Vaz S, Vermard Y, Marchal P (2014) Spatial interactions between saithe (Pollachius virens) and hake (Merluccius merluccius) in the North Sea. ICES J Mar Sci 71:1342-1355
Cushing DH (1990) Plankton production and year-class strength in fish populations: an update of the match/ mismatch hypothesis. Adv Mar Biol 26:249-293

Czajkowski T, Bolte A (2006) Unterschiedliche Reaktion deutscher und polnischer Herkünfte der Buche (Fagus sylvatica L.) auf Trockenheit. Allg Forst Jagdztg 176:133-143

Czajkowski T, Kühling M, Bolte A (2005) Einfluss der Sommertrockenheit im Jahre 2003 auf das Wachstum von Naturverjüngungen der Buche (Fagus sylvatica L.) im nordöstlichen Mitteleuropa. Allg Forst Jgdz 176:133-143

Defra (2013) Economics of climate resilience: natural environment theme - sea fish. Department for Environment, Food \& Rural Affairs (DEFRA)

Döbbeler H, Spellmann H (2002) Methodological approach to simulate and evaluate silvicultural treatments under climate change. Forstwiss Cent 121:52-69

Drinkwater KF (2005) The response of Atlantic cod (Gadus morhua) to future climate change. ICES J Mar Sci 62:1327-1337

Dulvy NK, Rogers SI, Jennings S, Stelzenmüller V, Dye SR, Skjoldal HR (2008) Climate change and deepening of the North Sea fish assemblage: a biotic indicator of warming seas. J Appl Ecol 45:1029-1039

Ellenberg H (1996) Vegetation Mitteleuropas mit den Alpen in ökologischer, dynamischer und historischer Sicht. Ulmer, Stuttgart

Engelhard GH, Pinnegar JK, Kell LT, Rijnsdorp AD (2011) Nine decades of North Sea sole and plaice distribution. ICES J Mar Sci 68:1090-1104

Engelhard GH, Righton DA, Pinnegar JK (2014) Climate change and fishing: a century of shifting distribution in North Sea cod. Glob Change Biol 20:2473-2483

Erler J, Becker G, Spellmann H, Dieter M, Ammer A, Bauhus J, Bitter A, Bolte A, Knoke T, Köhl M, Mosandl R, Möhring B, Schmidt O, von Teuffel K (2012) Einseitig, widersprüchlich und teilweise falsch. Holz Zentralbl 32:810-811 Escherich K (1931) Die Forstinsekten Mitteleuropas. Parey, Berlin

EU (2009) RICHTLINIE 2009/28/EG DES EUROPÄISCHEN PARLAMENTS UND DES RATES vom 23. April 2009 zur Förderung der Nutzung von Energie aus erneuerbaren Quellen und zur Änderung und anschließenden Aufhebung der Richtlinien 2001/77/EG und 2003/30/EG. Amtsblatt der Europäischen Union L140/16.

Fabry VJ, Seibel BA, Feely RA, Orr JC (2008) Impacts of ocean acidification on marine fauna and ecosystem processes. ICES J Mar Sci 65:414-432

FAOSTAT (2014) FAOSTAT database. Food and Agriculture Organization of the United Nations, Rome

Fischer A, Jantsch MC, Müller-Kroehling S (2014) Buchenwald-Lebensgemeinschaften im Klimawandel. Allg Forst Jagdztg 185:71-81

Fischer R, Dobbertin M, Granke O, Karoles K, Köhl M, Kraft P, Meyer P, Mues V, Lorenz M, Nagel H-D, Seidling W (2006) The condition of forests in Europe. Executive Report. UN/ECE, ICP-Forests, Hamburg

Flessa H, Müller D, Plassmann K, Osterburg B, Techen AK, Nitsch H, Nieberg H, Sanders J, Meyer zu Hartlage O, Beckmann E, Anspach V (2012) Studie zur Vorbereitung einer effizienten und gut abgestimmten Klimaschutzpolitik für den Agrarsektor. Landbauforschung - vTI Agriculture and Forestry Research Sonderheft 361

Franke A, Clemmesen C (2011) Effect of ocean acidification on early life stages of Atlantic herring (Clupea harengus L.). Biogeosciences 8:3697-3707

Franzaring J, Henning-Muller I, Funk R, Hermann W, Wulfmeyer V, Claupein W, Fangmeier A (2007) Effects of solar, climatic and atmospheric components on historical crop yields. Gefahrstoffe Reinhaltung Luft 67:251-258

Gazeau FPH, Gattuso JP, Dawber C, Pronker AE, Peene F, Peene J, Heip CHR, Middelburg JJ (2010) Effect of ocean acidification on the early life stages of the blue mussel Mytilus edulis. Biogeosciences 7:2051-2060

Gnoth L (2015) Einfluss von erhöhtem atmosphärischen $\mathrm{CO}_{2}$ auf das Wachstum und die Blattentwicklung von Vitis vinifera. Bachelor-Arbeit am Zentrum Holzwirtschaft (Fachbereich Biologie). Universität Hamburg, Hamburg

Graham-Rowe D (2012) Tank gegen Teller (Spektrum der Wissenschaft. Webseite von Spektrum)

Gröger JP, Kruse GH, Rohlf N (2010) Slave to the rhythm: how large-scale climate cycles trigger herring (Clupea harengus) regeneration in the North Sea. ICES J Mar Sci 67:454-465

Hale R, Calosi P, McNeill L, Mieszkowska N, Widdicombe S (2011) Predicted levels of future ocean acidification and temperature rise could alter com- 
munity structure and biodiversity in marine benthic communities. Oikos 120:661-674

Harris NL, Brown S, Hagen SC, Saatchi SS, Petrova S, Salas W, Hansen MC, Potapov PV, Lotsch A (2012) Baseline map of carbon emissions from deforestation in tropical regions. Science 336:1573-1576

Harvell CD, Kim K, Burkholder JM, Colwell RR, Epstein PR, Grimes DJ, Hofmann EE, Lipp EK, Osterhaus ADME, Overstreet RM, Porter JW, Smith GW, Vasta GR (1999) Emerging marine diseases-climate links and anthropogenic factors. Science 285:1505-1510

Hastie L, Pierce G, Pita C, Viana M, Smith J, Wangvoralak S (2009) Squid fishing in UK waters. A report to SEAFISH industry authority. School of Biological Sciences, University of Aberdeen, Aberdeen

Hättenschwiler S, Miglietta F, Raschi A, Körner C (1997) Thirty years of in situ tree growth under elevated $\mathrm{CO} 2$ : a model for future forest responses? Glob Change Biol 3:436-471

Heath MR, Brander K (2001) Workshop on Gadoid stocks in the North Sea during the 1960 s and 1970s. The fourth ICES/GLOBEC backward-facing workshop, 1999. Ices Coop Res Rep 244:1-55

Hendriks IE, Duarte CM, Alvarez M (2010) Vulnerability of marine biodiversity to ocean acidification: a meta-analysis. Est Coast Shelf Sci 86:157-164

Hiddink JD, ter Hofstede R (2008) Climate induced increases in species richness of marine fishes. Glob Chan Biol 14:453-460

IAB - Institut für Arbeitsmarkt und Berufsforschung (2013) Daten zur kurzfristigen Entwicklung von Wirtschaft und Arbeitsmarkt 04/2013

IPCC (2006) Guidelines for national greenhouse gas inventories. Institute for Global Environmental Strategies (IGES), Japan

Jansen T, Gislason H (2011) Temperature affects the timing of spawning and migration of North Sea mackerel. Cont Shelf Res 31:64-72

Jansen T, Kristensen K, Payne M, Edwards M, Schrum C, Pitois S (2012) Long-term retrospective analysis of mackerel spawning in the North Sea: a new time series and modeling approach to CPR data. PLOS ONE 7:e38758

Jones MC, Dye SR, Pinnegar JK, Warren R, Cheung WWL (2012) Modelling commercial fish distributions: prediction and assessment using different approaches. Ecol Model 225:133-145

Kätzel R (2008) Klimawandel. Zur genetischen und physiologischen Anpassungsfähigkeit der Baumarten. Arch Forstwes Landschaftsökol 42:9-15

Keckl G (2005) Obst in Niedersachsen. In: Kommunikationstechnologie, K.f.S. (Hrsg) Mitteilungen des Obstbauversuchsrings des Alten Landes

van Keeken OA, van Hoppe M, Grift RE, Rijnsdorp AD (2007) Changes in the spatial distribution of North Sea plaice (Pleuronectes platessa) and implications for fisheries management. J Sea Res 57:187-197

Kempf A, Stelzenmüller V, Akimova A, Floeter J (2014) Spatial assessment of predator-prey relationships in the North Sea: the influence of abiotic habitat properties on the spatial overlap between 0-group cod and grey gurnard. Fish Oceanogr 22:174-192

Kiefer L, Menzel F, Bahrs E (2014) The effect of feed demand on greenhouse gas emissions and farm profitability for organic and conventional dairy farms. J Dairy Sci 97:7564-7574

Kimball BA, Kobayashi K, Bindi M (2002) Responses of agricultural crops to freeair CO2 enrichment. Adv Agron 77:293-368

Knauf M, Köhl M, Mues V, Olschofsky K, Frühwald A (2015) Modeling the $\mathrm{CO}_{2}$ effects of forest management and wood usage on a regional basis. Carbon Balance Manag. https://cbmjournal.springeropen.com/articles/10.1186/ s13021-015-0024-7. Zuletzt zugegriffen am 24.08.2017

Knight L, Huff M, Stockhausen JI, Ross RJ (2005) Comparing energy use and environmental emissions of reinforced wood doors and steel doors. For Prod J 58(6):48-52

Köhl M, Lasco R, Cifuentes M, Jonsson Ö, Korhonen KT, Mundhenk P, de Jesus Navar J, Stinson G (2015) Changes in forest production, biomass and carbon: results from the 2015 UN FAO Global Forest Resources Assessment. Forest Ecol Manag 352:21-34

Kölling C (2007) Klimahüllen für 27 Waldbaumarten. AFZ Wald 23:1242-1245

Kraus G, Döring R (2013) Die Gemeinsame Fischereipolitik der EU: Nutzen, Probleme und Perspektiven eines pan-europäischen Ressourcenmanagements. Z Umweltr 1:3-9

Kriebitzsch W-U, Beck W, Schmitt U, Veste M (2008) Bedeutung trockener Sommer für Wachstumsfaktoren von verschiedenen Herkünften der Buche. AFZ Wald 5:246-248
Kroeker KJ, Kordas RL, Crim RN, Singh GG (2010) Meta-analysis reveals negative yet variable effects of ocean acidification on marine organisms. Ecol Lett 13:1419-1434

Le Quéré C, Moriarty R, Andrew RM, Peters GP, Ciais P, Friedlingstein P, Jones SD, Sitch S, Tans P, Arneth A, Boden TA, Bopp L, Bozec Y, Canadell JG, Chini LP, Chevallier F, Cosca CE, Harris I, Hoppema M, Houghton RA, House JI, Jain AK, Johannessen T, Kato E, Keeling RF, Kitidis V, Klein Goldewijk K, Koven C, Landa CS, Landschützer P, Lenton A, Lima ID, Marland G, Mathis JT, Metzl N, Nojiri Y, Olsen A, Ono T, Peng S, Peters W, Pfeil B, Poulter B, Raupach MR, Regnier P, Rödenbeck C, Saito S, Salisbury JE, Schuster U, Schwinger J, Séférian R, Segschneider J, Steinhoff T, Stocker BD, Sutton AJ, Takahashi $T$, Tilbrook B, van der Werf GR, Viovy N, Wang Y-P, Wanninkhof R, Wiltshire A, Zeng N (2015) Global carbon budget 2014. Earth Syst Sci Data 7:47-85 Le Quesne WJF, Pinnegar JK (2012) The potential impacts of ocean acidification: scaling from physiology to fisheries. Fish Fish 13:333-344

Lenoir S, Beaugrand G, Lecuyer E (2011) Modelled spatial distribution of marine fish and projected modifications in the North Atlantic Ocean. Glob Change Biol 17:115-129

Lindner M, Garcia-Gonzales J, Kolström M, Green T, Reguera R, Maroschek M, Seidl R, Lexer MJ, Netherer S, Schopf A, Kremer A, Delzon A, Barbati A, Marchetti $M$, Corona $P$ (2008) Impacts of climate change on European forests and options for adaptation. Report to the European Commission directorate-general for agriculture and rural development, AGRI-2007-G4-06

Link JS, Nye JA, Hare JA (2011) Guidelines for incorporating fish distribution shifts into a fisheries management context. Fish Fish 12:461-469

Llopiz JK, Cowen RK, Hauff MJ, Ji R, Munday PL, Muhling BA, Peck MA, Richardson DE, Sogard S, Sponaugle S (2014) Early life history and fisheries oceanography: new questions in a changing world. Oceanography 27(4):26-41

Lotfiomran N, Fromm J, Luinstra GA (2015) Effects of elevated $\mathrm{CO}_{2}$ and different nutrient supplies on wood structure of european beech (Fagus sylvatica) and gray poplar (Populus $x$ canescens). IAWA J 36:84-97

Luyssaert S, Schulze ED, Börner A, Knohl A, Hessenmöller D, Law BE, Ciais P, Grace J (2008) Old-growth forests as global carbon sinks. Nature 455:213215

Lynam CP, Hay SJ, Brierley AS (2004) Interannual variability in abundance of North Sea jellyfish and links to the North Atlantic oscillation. Limnol Oceanogr 49:637-643

Manderscheid R, Weigel H-J (2007) Drought stress effects on wheat are mitigated by atmospheric $\mathrm{CO}_{2}$ enrichment. Agron Sustain Dev 27:79-87

Matyssek R, Fromm J, Rennenberg H, Roloff A (2010) Biologie der Bäume - von der Zelle zur globalen Ebene. UTB, Stuttgart

Mayer H (1999) Waldbau- auf soziologisch-ökologischer Grundlage. Springer, Heidelberg

Mendiola D, Alvarez P, Cotano U, Martínez de Murguía A (2007) Early development and growth of the laboratory reared north-east Atlantic mackerel Scomber scombrus L. J Fish Biol 70:911-933

Menzel A, Fabian P (1999) Growing season extended in Europe. Nature 397:659

Menzel A, Sparks TH, Estrella N, Roy DB (2006) Altered geographical and temporal variability in response to climate change. Global Ecol Biogeogr 15:498-504

Merino G, Barange M, Mullon C (2010) Climate variability and change scenarios for a marine commodity: modelling small pelagic fish, fisheries and fishmeal in a globalized market. J Marine Syst 81:196-205

Montero-Serra I, Edwards M, Genner MJ (2015) Warming shelf seas drive the subtropicalization of European pelagic fish communities. Glob Change Biol 21:144-153

Müller M (2009) Auswirkungen des Klimawandels auf ausgewählte Schadfaktoren in den deutschen Wäldern. Wiss Z TU Dresd 58:69-75

Nash RDM, Dickey-Collas M (2005) The influence of life history dynamics and environment on the determination of year class strength in North Sea herring (Clupea harengus L.). Fish Oceanogr 14:279-291

O'Brien CM, Fox CJ, Planque B, Casey J (2000) Climate variability and North Sea cod. Nature 404:142

OECD (2002) Study on the effects of climate change on agriculture. In: Development, organisation for economic co-operation and development. Joint Working Party on Agriculture and the Environment, COM/AGR/CA/ EN/EPOC(2002)98. OECD, Paris, S 33

Olesen JE, Bindi M (2004) Agricultural impacts and adaptations to climate change in Europe. Farm Policy J 1:36-46 
Osterburg B, Kätsch S, Wolff A (2013) Szenarioanalysen zur Minderung von Treibhausgasemissionen der deutschen Landwirtschaft im Jahr 2050 Thünen Report 13

Otto HJ (1994) Waldökologie. Ulmer, Stuttgart

Pawson MG (1992) Climatic influences on the spawning success, growth and recruitment of bass (Dicentrarchus labrax L.) in British waters. ICES Mar Sci Symp 195:388-392

Pawson MG, Kupschus S, Pickett GD (2007) The status of sea bass (Dicentrarchus labrax) stocks around England and Wales, derived using a separable catchat-age model, and implications for fisheries management. ICES J Mar Sci 64:346-356

Perry AL, Low PJ, Ellis JR, Reynolds JD (2005) Climate change and distribution shifts in marine fishes. Science 308:1912-1915

Petercord R, Leonhard S, Muck M, Lemme H, Lobinger G, Immler T, Konnert M (2009) Klimaänderung und Forstschädlinge. LWF Aktuell 72:4-7

Petitgas P, Alheit J, Peck MA, Raab K, Irigoien X, Huret M, van der Kooij J, Pohlmann T, Wagner C, Zarraonaindia I, Dickey-Collas M (2012) Anchovy population expansion in the North Sea. Mar Ecol Prog Ser 444:1-13

Pingoud K, Pohjola J, Valsta L (2010) Assessing the Integrated climatic impacts of forestry and wood products. Silva Fennica 44:155-175

Planque B, Frédou T (1999) Temperature and the recruitment of Atlantic cod (Gadus morhua). Can J Fish Aquat Sci 56:2069-2077

Pörtner H-O, Karl DM, Boyd PW, Cheung WWL, Lluch-Cota SE, Nojiri Y, Schmidt DN, Zavialov PO (2014) Ocean systems. In: Field CB, Barros VR, Dokken DJ, Mach KJ, Mastrandrea MD, Bilir TE, Chatterjee M, Ebi KL, Estrada YO, Genova RC, Girma B, Kissel ES, Levy AN, MacCracken S, Mastrandrea PR, White LL (Hrsg) Climate change 2014: impacts, adaptation, and vulnerability. Part A: global and sectoral aspects. Contribution of working group II to the fifth assessment report of the intergovernmental panel on climate change. Cambridge University Press, Cambridge, New York, S 411-484

Rahmann G, Aulrich K, Barth K, Böhm H, Koopmann R, Oppermann R, Paulsen HM, Weißmann F (2008) Die Klimarelevanz des ökologischen Landbaus Stand des Wissens. Landbauforsch vTi Agric For Res 58:71-89

Reid PC, Borges MF, Svendsen E (2001) A regime shift in the North Sea circa 1988 linked to changes in the North Sea horse mackerel fishery. Fish Res 50:163-171

Reid PC, Edwards M, Beaugrand G, Skogen M, Stevens D (2003) Periodic changes in the zooplankton of the North Sea during the twentieth century linked to oceanic inflow. Fish Oceanogr 12:260-269

Roloff A, Grundmann B (2008) Klimawandel und Baumarten-Verwendung für Waldökosysteme. Forschungsbericht. TU Dresden, Tharandt, S 46

Russ A, Rieck W, Martin J (2011) Zustand und Wandel der Waldböden Mecklenburg-Vorpommerns. Mitt Forstl Versuchswes Mecklenburg Vorpommern 9:11-108

Rüter S, Rock J, Köthke M, Dieter M (2011) Wie viel Holznutzung ist gut fürs Klima? AFZ Wald 15:19-21

Sachverständigenrat Umwelt (2012) Umweltgutachten 2012: Verantwortung in einer begrenzten Welt. Schmidt, Berlin

Sathre R, O'Connor J (2010) Meta-analysis of greenhouse gas displacement factors of wood product substitution. Environ Sci Policy 13:104-114

Schaller M, Weigel H-J (2007) Analyse des Sachstands zu Auswirkungen von Klimaveränderungen auf die deutsche Landwirtschaft und Maßnahmen zur Anpassung. In: Landbauforschung Völkenrode - FAL Agricultural Research. FAL, Braunschweig, S 247

Scharai-Rad M, Welling J (2002) Environmental and energy balances of wood products and substitutes. FAO, Rome

Schmidt-Vogt H (1988) Die Fichte. Parey, Hamburg, Berlin

Schulze S, Kowalewski J, Döll S (2011) Querschnittsaufgabe Q3: Ökonomie. http://klimzug-nord.de/index.php/page/2009-04-06-Oekonomie. Zuletzt zugegriffen am 24.08.2017

Schwerdtfeger F (1970) Die Waldkrankheiten. Parey, Hamburg

Simpson SD, Jennings S, Johnson MP, Blanchard JL, Schön P-J, Sims DW, Genner MJ (2011) Continental shelf-wide response of a fish assemblage to rapid warming of the sea. Curr Biol 21:1565-1570

Skinner C, Gattinger A, Muller A, Mäder P, Fließbach A, Stolze M, Ruser R, Niggli U (2014) Greenhouse gas fluxes from agricultural soils under organic and non-organic management - a global meta-analysis. Sci Total Environ 468:553-563
Statistisches Amt für Hamburg und Schleswig Holstein (2013) Arbeitskräfte in Hamburg und Schleswig-Holstein 2010, Endgültige Ergebnisse der Landwirtschaftszählung 2010. In: Nord S (Hrsg) Statistische Berichte. Statistisches Amt für Hamburg und Schleswig Holstein, Hamburg

Statistische Ämter des Bundes und der Länder (2015) Regionaldatenbank Deutschland. Statistische Ämter des Bundes und der Länder, Düsseldorf

von Storch H, Claussen M (Hrsg) (2011) Klimabericht für die Metropolregion Hamburg. Springer, Heidelberg

Styf HK, Nilsson Sköld H, Eriksson SP (2013) Embryonic response to long-term exposure of the marine crustacean Nephrops norvegicus to ocean acidification and elevated temperature. Ecol Evol 3:5055-5065

Tesche M (1992) Klimaresistenz. In: Lyr H, Fiedler H-J, Tranquillini W (Hrsg) Physiologie und Ökologie der Gehölze. Fischer, Jena, S 279-306

Thomson JD (2010) Flowering phenology, fruiting success and progressive deterioration of pollination in early-flowering geophyte. Philos Trans $\mathrm{R}$ Soc Lond B Biol Sci 365:3187-3199

Tubiello FN, Salvatore M, Cóndor Golec RD, Ferrara A, Rossi S, Biancalani R, Federici S, Jacobs H, Flammini A (2014) Agriculture, forestry and other land use: Emissions by sources and removals by sinks. 1990-2011 Analysis. In: FAO Statistics Division (Hrsg) Working paper series ESS/14-02

Umweltbundesamt (2014) Berichterstattung unter der Klimarahmenkonvention der Vereinten Nationen und dem Kyoto-Protokoll 2014, Nationaler Inventarbericht zum Deutschen Treibhausgasinventar 1990-2012. In: Umweltbundesamt (Hrsg) Climate change 24/2014. Umweltbundesamt, Dessau, S 965

Vermeulen SJ, Campbell BM, Ingram JSI (2012) Climate change and food systems. Annu Rev Environ Resour 37:195-222

Weigel HJ, Pacholski A, Waloszczyk K, Frühauf $C$, Manderscheid R, Anderson TH, Heinemeyer O, Kleikamp B, Helal M, Burkart S, Schrader S, Sticht C, Giesemann A (2006) Effects of elevated atmospheric $\mathrm{CO}_{2}$ concentrations on barley, sugar beet and wheat in a rotation, examples from the Braunschweig carbon project. Landbauforsch Völkenrode 56(3-4):101-115

van der Werf GR, Morton DC, DeFries RS, Olivier JGJ, Kasibhatla PS, Jackson $\mathrm{RB}$, Collatz GJ, Randerson JT (2009) $\mathrm{CO}_{2}$ emissions from forest loss. Nat Geosci 2:737-738

Open Access Dieses Kapitel wird unter der Creative Commons Namensnennung - Nicht kommerziell 4.0 International Lizenz (http://creativecommons.org/licenses/by-nc/4.0/deed.de) veröffentlicht, welche die nicht-kommerzielle Nutzung, Vervielfältigung, Bearbeitung, Verbreitung und Wiedergabe in jeglichem Medium und Format erlaubt, sofern Sie den/die ursprünglichen Autor(en) und die Quelle ordnungsgemäß nennen, einen Link zur Creative Commons Lizenz beifügen und angeben, ob Änderungen vorgenommen wurden.

Die in diesem Kapitel enthaltenen Bilder und sonstiges Drittmaterial unterliegen ebenfalls der genannten Creative Commons Lizenz, sofern sich aus der Abbildungslegende nichts anderes ergibt. Sofern das betreffende Material nicht unter der genannten Creative Commons Lizenz steht und die betreffende Handlung nicht nach gesetzlichen Vorschriften erlaubt ist, ist auch für die oben aufgeführten nicht-kommerziellen Weiterverwendungen des Materials die Einwilligung des jeweiligen Rechteinhabers einzuholen. 